\title{
The Effect of Marketing Deceptive Practices on the Organizational Mental Image from Customer Viewpoint (Analytical Study of the Insurance Industry)
}

\author{
Majed Abdul Amir Mohsen \\ Ahmad Abdul Reda Enad \\ College of Administration and Economics, University of Al-Qadisiyah \\ Majed.Mehsin@qu.edu.iq_abuehmeed2021@gmail.com
}

Submission date:- 5/8/2018 Acceptance date:- 26/9/2018 Publication date:- 23/1/2019

Keywords: marketing deceptive practices, unethical maketing issues, organizational mental image.

\begin{abstract}
This study aimed to address the concept of deceptive marketing in the most important activity of companies, i.e., marketing, which is the lifeline on which companies depend in the process of financing and product selling. Additionally, through marketing, companies can communicate directly with customers, and this activity includes marketing practices that are deceptive or misleading. The study dealt with the presentation of the components of the marketing mix, and how each component can include deceptive or misleading practices. Marketers practice customer manipulation with the intention of changing customers' behavior and attitudes towards achieving the greatest possible profit in lesser time. With the spread of marketing deception and marketing fraud in various areas, the phenomenon is growing not only in product marketing, but also in service marketing, especially insurance services, as many marketers and sales representatives believe that success and profit making is associated with those practices. The study addressed many factors facilitating these practices, as well as the ways in which marketing deception is practiced and the impact of such practice on the perceptions that form in the minds of customers about companies. One of the most important objectives of the study was to substantiate the relationship between the dimensions of marketing deception and the dimensions of the mental image of the organization by relying on the statistical analysis of the initial data of the study, which was collected through questionnaire that was prepared for this purpose and distributed to a random sample of 225 customers of insurance companies operating in the insurance market in Iraq.

The most important findings of the study show that deceptive marketing practiced through service marketing mix, among other dimensions, affects the mental image that the customers hold towards the organization in negative and varying ways. This study presents a number of recommendations, the foremost of which is the necessity of educating marketers and companies about the negativity of deceptive practices on the company in the long term, as well as paying attention to the mental image held by customers towards the insurance companies because of its impact on the formation of positive impressions towards the company, and thus increasing market share of the company through its reputation in the insurance market .
\end{abstract}




\title{
تأثير ممارسات الخداع التسويقي في الصورة الذهنية للمنظمة من وجهة نظر الزبائن (در اسة تحليلية في قطاع التأمين)
}

\author{
ماجد عبد الاميز محسن احمد عبد الرضا عناد \\ فسم ادرارة الاعمال، كلبة الادارة و الافتصاد، جامعة القادسية \\ Majed.Mehsin@qu.edu.iq abuehmeed2021@gmail.com
}

الهدف من هذه الدراسة هو النطرق لمفهوم الخداع والتضليل التسويقي في واحد من أهم أنثطة الثركات وهو النشاط التسويقي والذي في

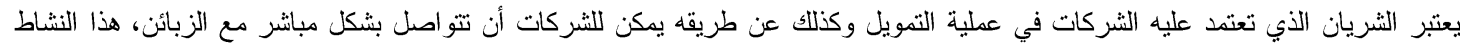

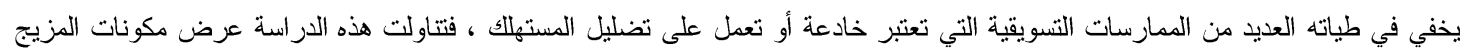

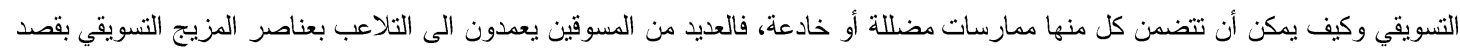

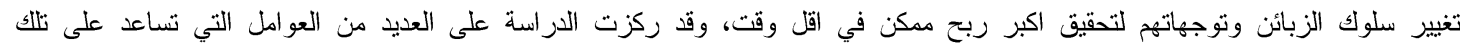

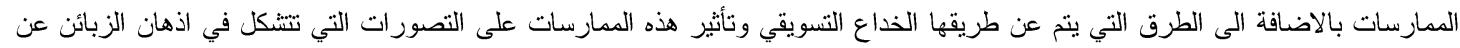

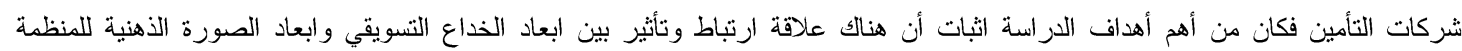

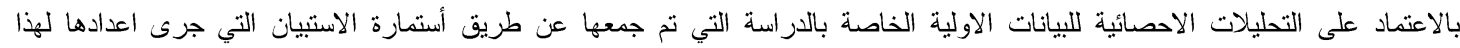

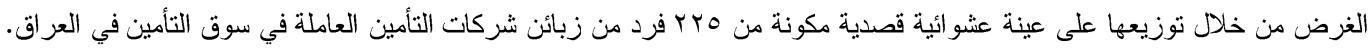

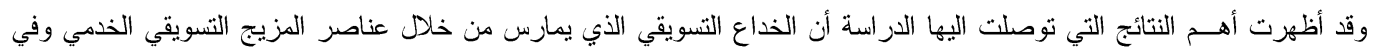

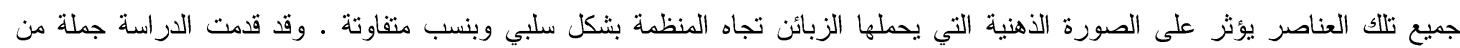
التوصيات يأتي في مقدمتها ضرورة تو عية المسوقين والثركات الى خطورة الممارسات الخادعة على الثركة في الامد الطويل، وكذلك الاهتمام

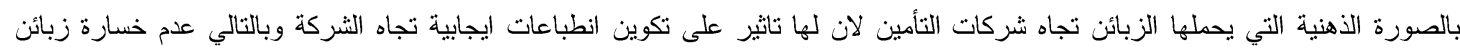

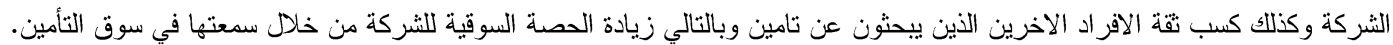

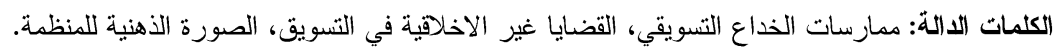

| Introduction المقدمة

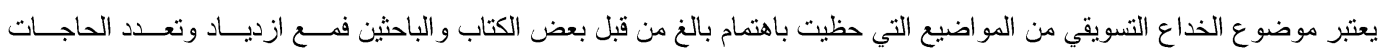

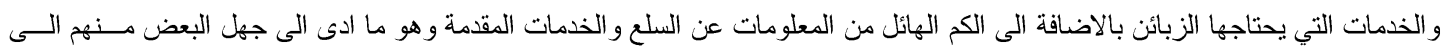

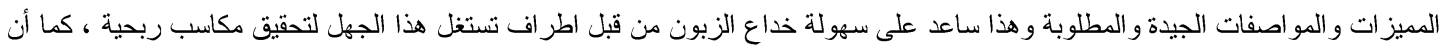

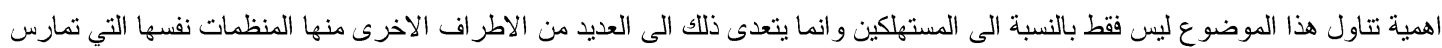

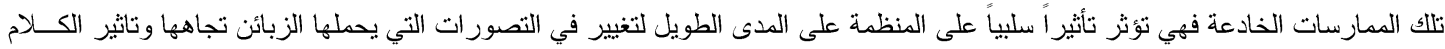

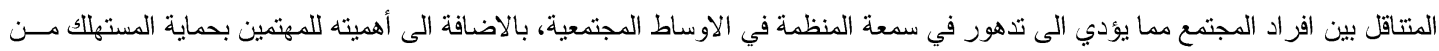

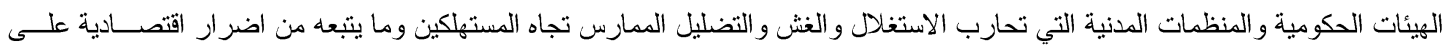

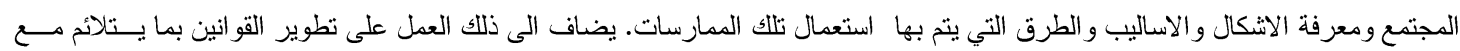

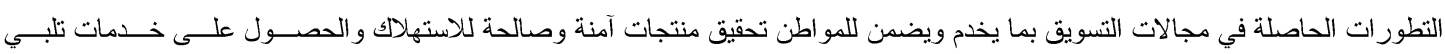
طموحسه.

وبغية تغطية ما تم ذكره من أهمية للمتغير ات قيد الدراسة فقد عمد الباحث لتكوين هيكلية الدراسة على اربعة مباحث رئيسية تتاول الفصل

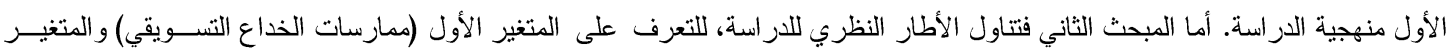

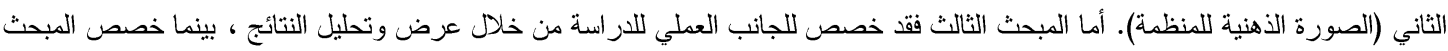

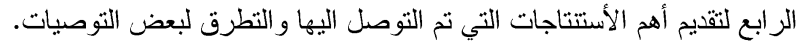




\section{ا - منهجية الدراسة}

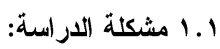

إن زيادة عدد شركات التأمين العاملة في السوق العر اقية وازدياد حدة المنافسة بين هذه الثركات ادى الى استخدام همارسات تتسم

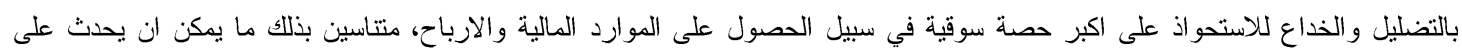

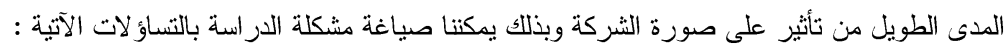

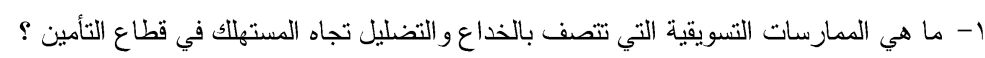

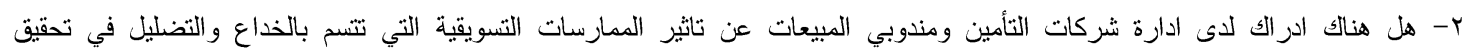
التصورات الذهنية السلبية لدى زبائن شركات التأمين.

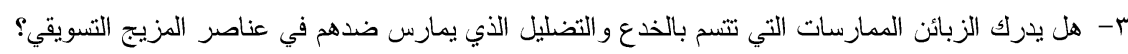

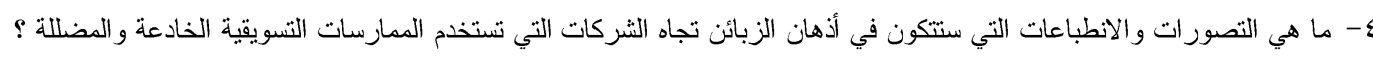

ץ.1 أهداف الاراسة: يمكن تلخيص أهداف الدراسة بجملة من النقاط الآتية : الاست

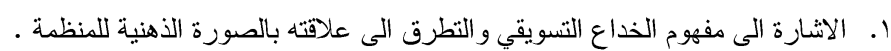

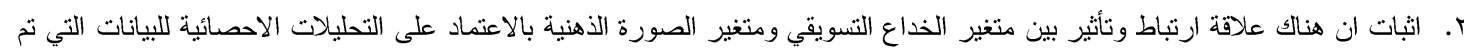

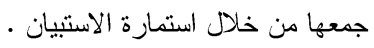

r. اعطاء صورة واضحة للمستهلك عن الممارسات التي تتسم بالخداع و التضليل و الآثار المتزتبة على زبائن شركات التأمين .

r.أهمية الار اسة: يمكن تلخيص اهمية الدراسة بجملة من النقاط التالية:

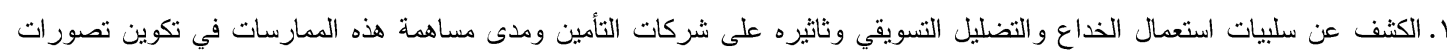

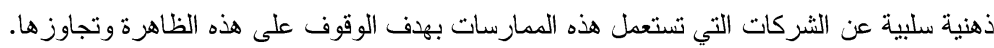

r. التعرف على اثكال الخداع و التضليل التي من المدكن ان تستعمل من قبل المسوقين ومندوبي المبيعات في شركات التأمين.

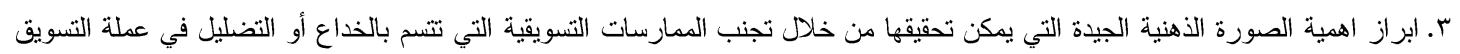

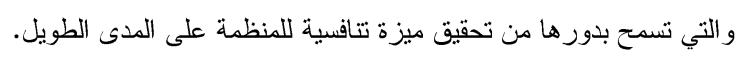

ع. أمنهج الاراسة: أعتمد الباحث على استعمال المنهج الوصفي التحليلي الذي ينضمن جمع البيانات والمعلومات عن الظاهرة المدروسة وتحليلها والكشف عن العلاقة بين المتغيرات. ه. 1 مجتمع وعينة الدراسة: اعتمد الباحث في هذه الدراسة على اكتثاف آراء المستهلكين بشأن الممارسات التسويقية التي تتسم بالخداع

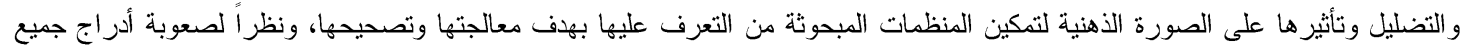

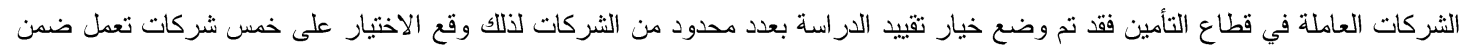

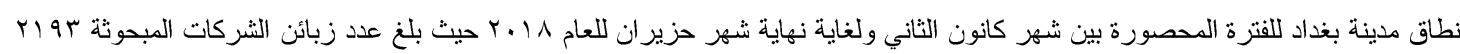

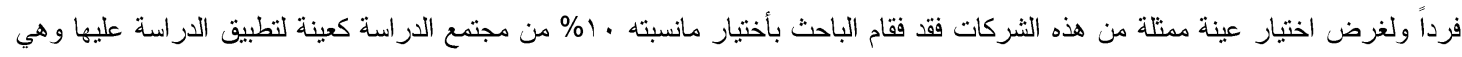

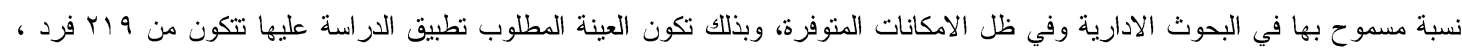

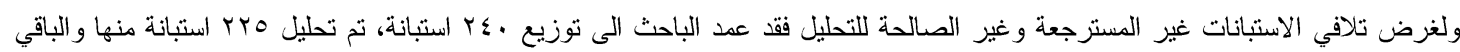

10 استبانة غير صالحة للتحليل، وبذلك يكون نسبة الاستبانات الصالحة للتحليل ؛ 9\% من مجموع الاستبانات الموزعة على عيلى عينة الدراسة.

r.l - P أساليب جمع البيانات وأدوات الاراسة:

اعتمدت الدراسة في إطاريها النظري والتطبيقي على عدات عدد من الأدوات كما موضح بالفقرات التالية:

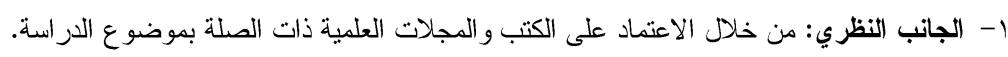

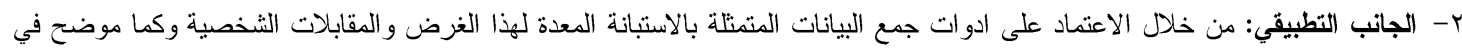
ادناه:

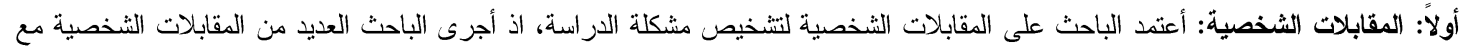

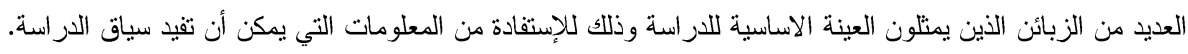

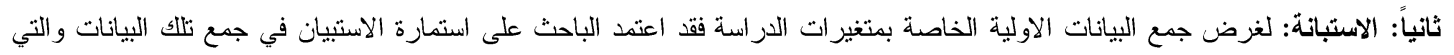

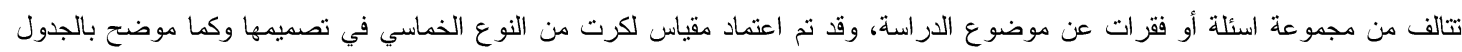
(1) وقد تضمنت الاستبانة محورين رئيسيين هما: 
المحور الأول: ويضم المعلومات و البيانات الثخصية لعينة الدراسة .

المحور الثاني: يضم هذا المحور المتغير المستقل المتمثل بالخداع التسويقي وابعاده والمتغير المعتمد المتمثل بالصورة الذهنية التي يحملها الزبائن

تجاه المنظمة.

جدول (1) مدرج ليكرت من النوع الخماسي

\begin{tabular}{|c|c|c|c|c|c|}
\hline لا أتفق تماماً & لا أتفق & غير متأكد & أتفق & أَتفق تماماً & الوزن \\
\hline 1 & r & r & $\varepsilon$ & 。 & الدرجة \\
\hline
\end{tabular}

و الجدول (r) يبين المتغيرات الخاصة بالاستبانة والابعاد المستخدمة لكل متغير وكذلك عدد الفقرات لكل بعد والمصادر المعتمدة في اعداد الاستبانة.

جدول (ץ) متغيرات الاراسة والابعاد المستخدمة وأهم المقاييس المستخدمة في إعداد الاستبانة

\begin{tabular}{|c|c|c|c|c|c|}
\hline 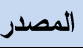 & تسلسل الفقرات & عدد الفقرات & 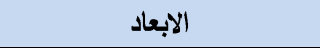 & المتغيرات & $ت$ \\
\hline \multirow{6}{*}{$\begin{array}{l}{[1]} \\
{[2]}\end{array}$} & $7-1$ & 4 & الخداع في الخدمة التأمينية & \multirow{6}{*}{ الخداع التسويقي } & \multirow{6}{*}{1} \\
\hline & $11-v$ & 0 & الخداع في السعر & & \\
\hline & $17-14$ & 0 & الخداع في التوزيع & & \\
\hline & $r)-I V$ & 0 & الخداع في الترويج & & \\
\hline & $M Y-M r$ & 0 & الخداع من قبل مقدمي الخدمة & & \\
\hline & $r_{1}-r V$ & 0 & الخداع في عملية تقديم الخدمة & & \\
\hline \multirow{2}{*}{ [3] } & $7-1$ & 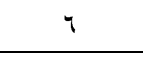 & البعد المعرفي ( الادر اكي ) & \multirow{3}{*}{ الصورة الذهنية } & \multirow{3}{*}{ r } \\
\hline & Ir $-V$ & 7 & البعد العاطفي ( الوجداني ) & & \\
\hline$[4]$ & $18-14$ & 0 & البعد السلوكي & & \\
\hline
\end{tabular}

\section{r. أختبارات صدق وثبات الاستبيان:}

بعد أن تم جمع مقياس الدراسة لكافة المتغيرات و الابعاد كان لابد من أخضاعهات الى ألى أختبار الصدق و الثبات وكما موضح ادناه:

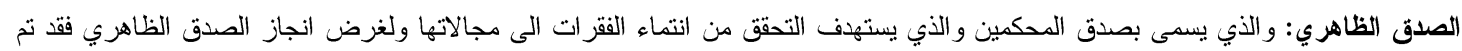

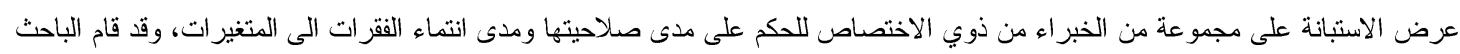

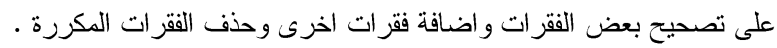
الصدق العام: يسمى في بعض الاحيان بالقوى التمييزية للفقزات، ويمكن الحصول على معامل الصدق عن طريق جذر معاملات الثرات الثبات وكما

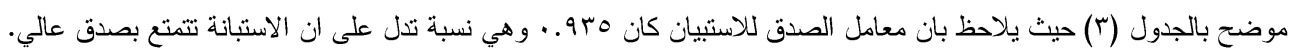

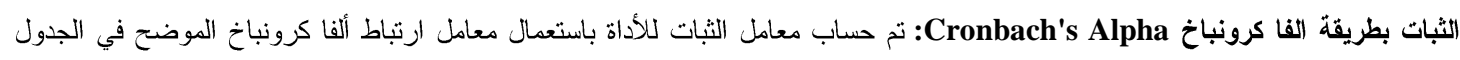

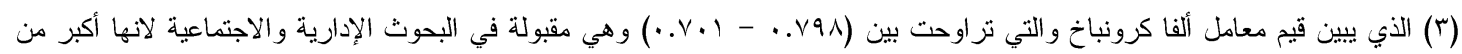

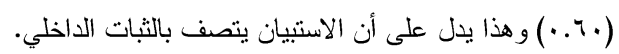


جدول (攵) معاملات الثبات و الصدق لأداة قياس الاراسة

\begin{tabular}{|c|c|c|c|c|c|}
\hline الصدق لكل بعد & $\begin{array}{c}\text { الفا كرونباخ لكل معامل } \\
\text { بعد }\end{array}$ & الابعاد & الصدق للمتغير & كرونباخ & المتغير \\
\hline 0.893 & 0.798 & الخداع في الخدمة التأمينية & \multirow{6}{*}{0.901} & \multirow{6}{*}{0.812} & \multirow{6}{*}{ ممارسات الخداع } \\
\hline 0.871 & 0.758 & الخداع في السعر & & & \\
\hline 0.844 & 0.713 & الذداع في التوزيع & & & \\
\hline 0.838 & 0.702 & الخداع في الترويج & & & \\
\hline 0.837 & 0.701 & الخداع من قبل مقدمي الخدمة & & & \\
\hline 0.883 & 0.779 & الخداع في عملية نقديم الخدمة & & & \\
\hline 0.867 & 0.752 & البعد المعرفي ( الادر اكي ) & \multirow{3}{*}{0.922} & \multirow{3}{*}{0.851} & \multirow{3}{*}{$\begin{array}{c}\text { الصورة الذهنية } \\
\text { للمنظمة } \\
\text { Y }\end{array}$} \\
\hline 0.860 & 0.740 & البعد العاطفي ( الوجداني ) & & & \\
\hline 0.876 & 0.768 & البعد السلوكي & & & \\
\hline 0.935 & 0.874 & \multicolumn{4}{|c|}{ جميع فقرات الاستبيان } \\
\hline
\end{tabular}

المصدر : من اعداد الباحث بالاعتماد على مخرجات نظام SPSS الاصدار ؟ كار

يمكن الحصول على الصدق عن طريق الجذر التربيعي للثبات (معامل الفا كرونباخ) كما في المعادلة التالية : $\mathrm{V}=\sqrt{R}$

؛ 1 ا المخطط الفرضي للار اسة:

تحتوي الدر اسة على متغيرين أسسيين هما المتغير المستقل الذي يمثلك ممارسات الذداع التسويقي والمتغير التابع و المتمثل بالصورة الذهنية

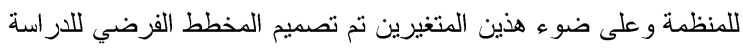

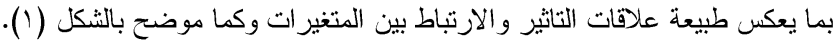

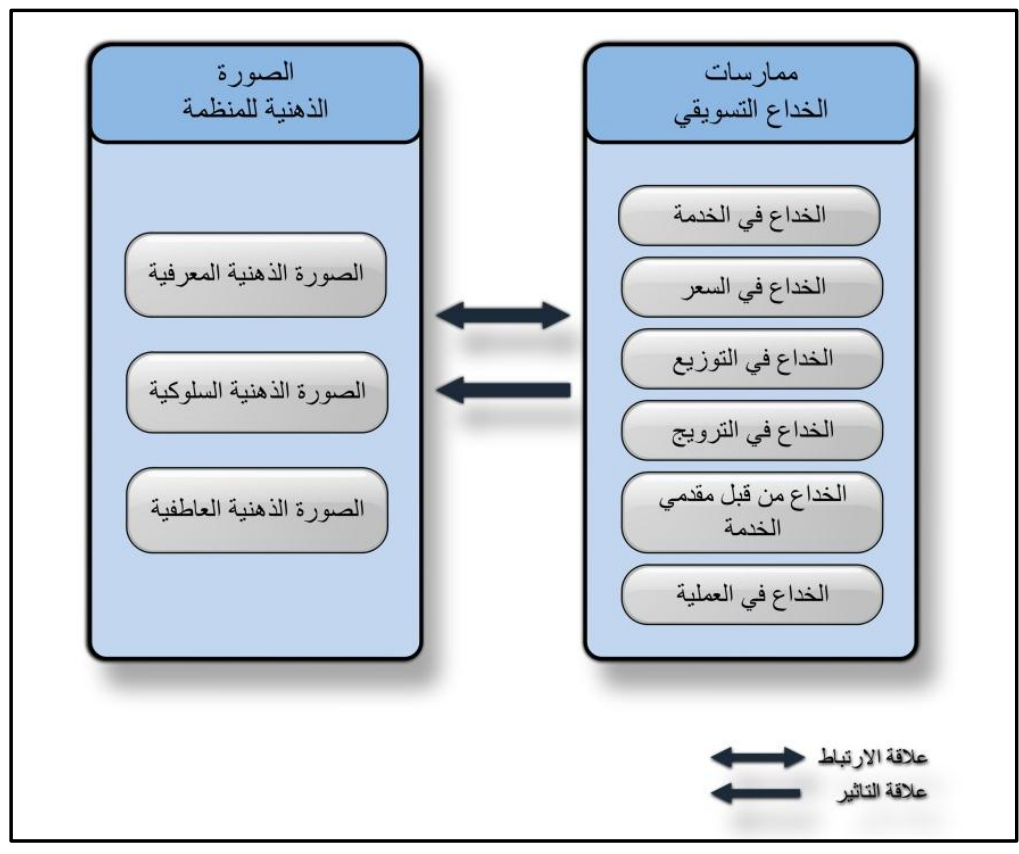

شكل (1) المخطط الفرضي للار اسة 
الفرضية الرئيسة الأولى: توجد علاقة ارتباط ذات دلالة معنوية بين أبعاد ممارسات الذذاع التسويقي (الذذاع في الذدمة التأمينية, الذاع في السعر , الذاع في التوزيع, الخداع في التزويج, الخداع من قبل مقدمي الخدمة, الخذاع في عملية تقديم الخدمة) والصورة الذهنية للمنظمة.

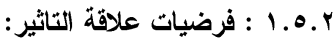

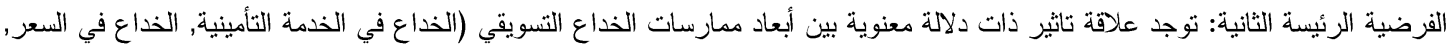

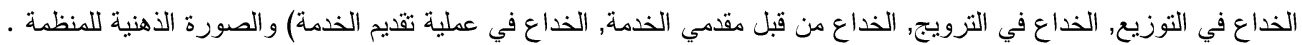

$$
\begin{aligned}
& \text { (الم الاساليب الاحصائية المتبعة في البحث }
\end{aligned}
$$

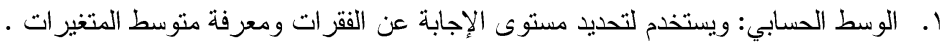

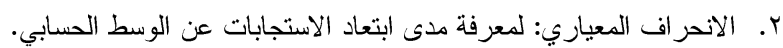

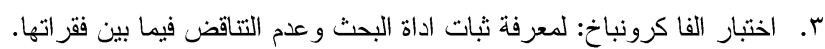

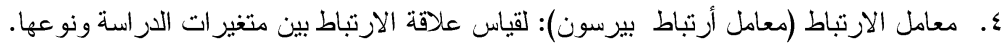

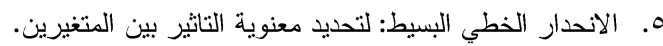

\section{r - الجانب النظري للار اسة}

ممارسات الخداع التسويقي

لقد عرف الخداع التسويقي من قبل Fayyaz\&Lodhi بانه واحد من القضايا الاخلاقية الهامة التي تحدث عن طريق الإعلان، وفي الواقع هو الاحساس بالتضليل الذي يجري باعتقاد المستهلكين وقد يتسبب في خسارة كبيرة في موارد الثركة المالية وكذلك على الصحة بالنسبة

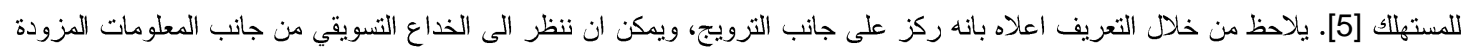

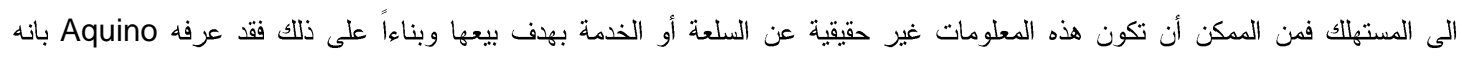

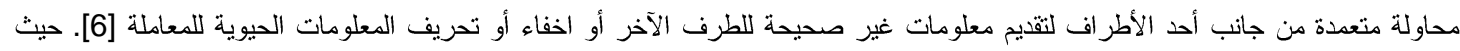

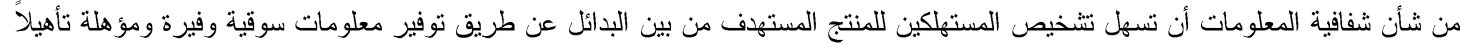

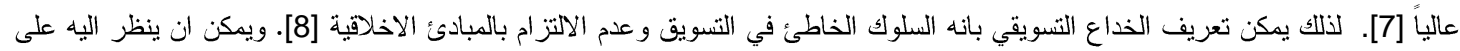

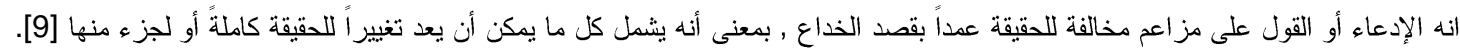

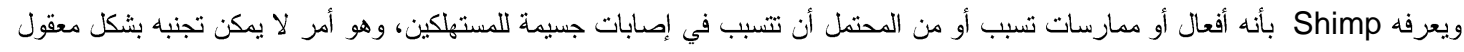

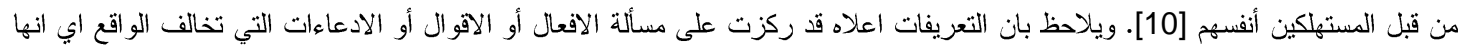

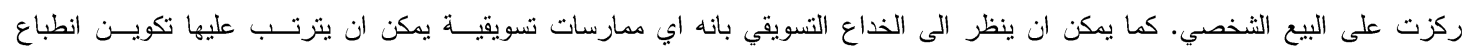

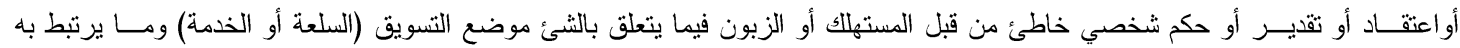

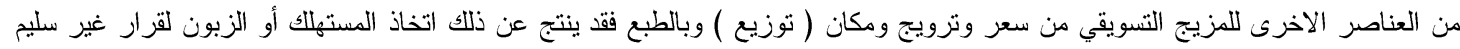

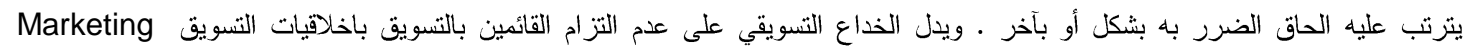

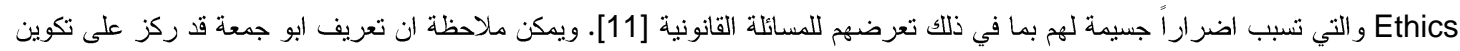

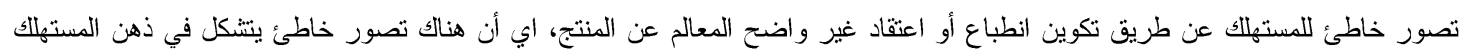
قد يكون قبل أو عند أو بعد عملية التعامل مع القائمين على التسويق بحيث ينتج عن ذلك التصور اتخاذ قرار شرائي غير سليم قد يلحق الضرر

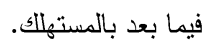
اما Staake \& Thiesse \& Fleisch فقد اتجهو الى النظر الى الخداع التسويقي من جانب المنتج المقلد أوالمزور والتجارة بها فقد

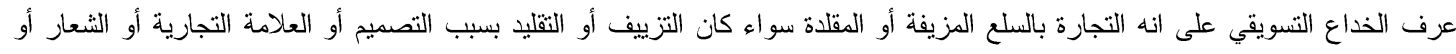
اسم الثركة أو استخدام العلامة التجارية دون اذن للثركة المصنعة أو ادراج علامة الجودة (مثل علامة الايزو) أو المطابقة القياسية للمنتجات

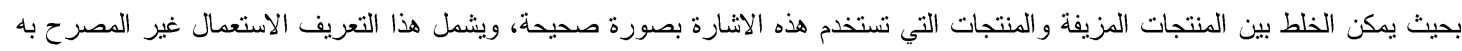

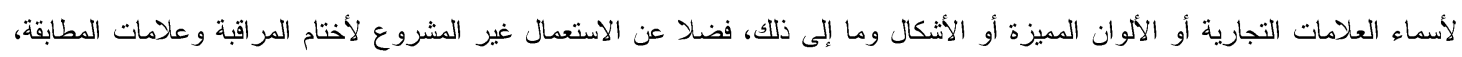

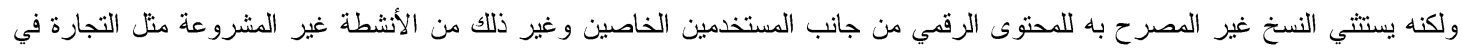

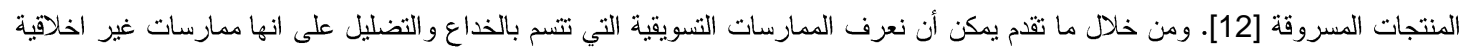

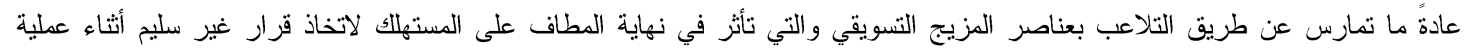




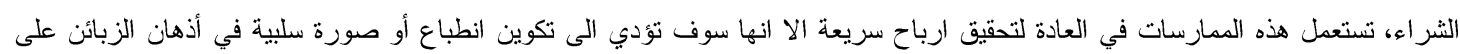

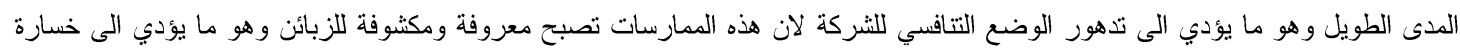

تتقسم عناصر الخداع التسويقي الى ثلاثة عناصر كما حددها [15],[14],[13]. وكما موضح في الفقرات التالية تبين ثلك العناصر :

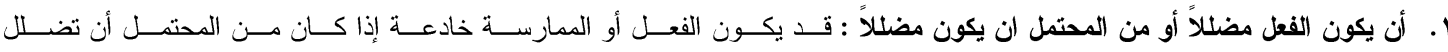

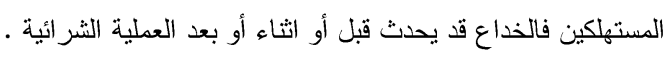

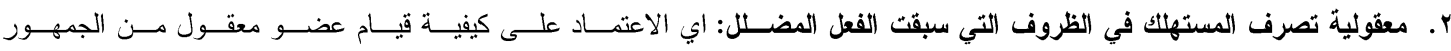

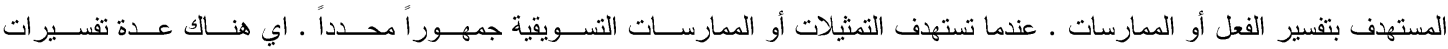
للفعل أو البيان أو يكون التفسير بشكل غير متساوي من قبل المستهلكين.

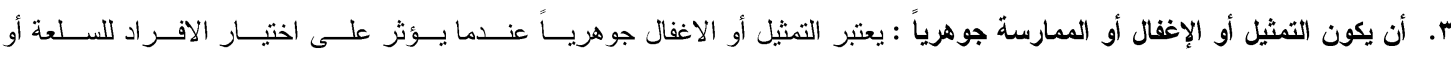

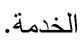

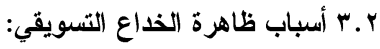

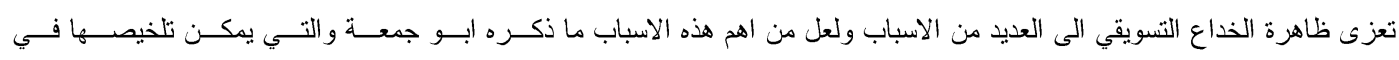

النقاط التالية [11]:

ا. عدم الادر الك من قبل المسوقين لمفهوم هذه الظاهرة والممارسات التي تتطوي تحتها وما تسببه من آثار و اضر ار بالغة بالمنظمة التي يعملون

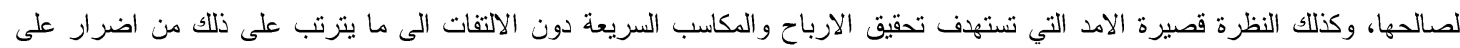
المدى الطويل. r. الدور الرقابي الذي يكاد ان يكون معدوم من قبل الجهات المختصة بحماية المستهلك بالاضافة الى الفساد الاداري المستشري.

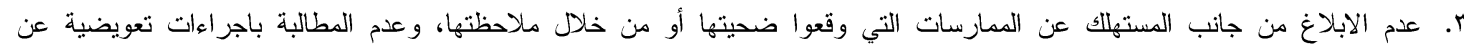
الاضرار التي تصيبهم نتيجة الخداع التسويقي. ع. قصور التشريعات والقو انين التي تحرم استعمال الممارسات التسويقية الخادعة، وكذلك القصور في الجزاءات التي تتزتب على من يثبت

استعماله لمثل هذه الممارسات و البطء بالاجر اءات التتفيذية من قبل الجهات المختصنة.

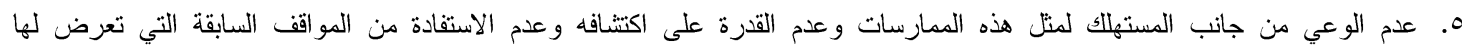
المستهلكون الاخرون.

\section{ك. Y اساليب ممارسة الخداع التسويقي:} ينظر الباحثون الى الذداع التسويقي من عدة جوانب وابعاد مختلفة فمنهم من يتوجه الى المنتج ومنهم من ينظر اليه من جانب السعر

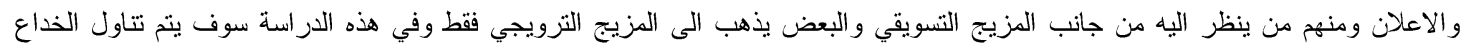
التسويقي من جانب المزيج التسويقي للذدمات لان هذه العناصر تعتبر جوهر العملية التسويقية أو جوهر انتطة التسويق.

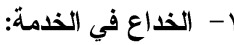

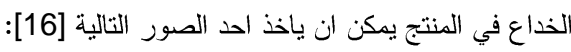
-الخداع التسويقي المتعلق بوضع العلامات على المنتجات: كاستخدام بطاقات الجودة المزيفة ومؤشرات المنشأ (بلد المنشأ والمنشأ الإقليمي) وتسمية المنتج -الخداع التسويقي المتعلق بجودة المنتج: التضليل من قبل البائع أو المسوق بشأن جودة السلع أو الخدمات. -الخداع التسويقي المتعلق بالتغليف: كتضليل المستهلك بشراء العبوة الكبيرة ضناً منه بانها سوف توفر له له المال فيما لو تم شراء العبوات الصغيرة. -الخداع التسويقي المتعلق بالتصميم: تظاهز المسوق بان لديه افضل نوعية واعلي جودة من المنتج.

ب- ب الخداع في السعر:

ويحدث الخداع في السعر عندما يتم تضليل المستهلكين عن طريق الأسعار التي تقدمها الثركات ويشمل ذلك ممارسات مثل [16].:

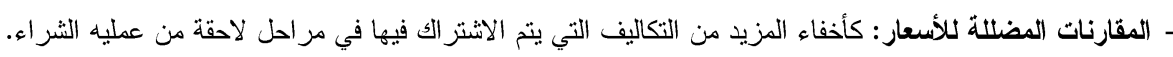

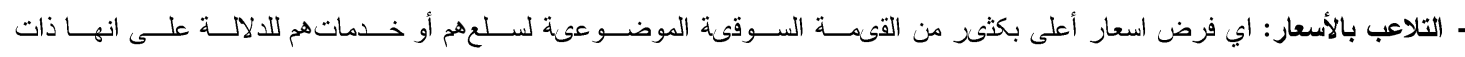

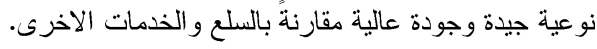




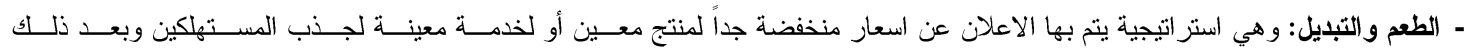

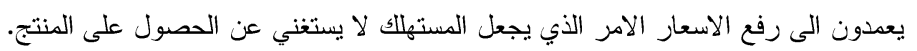

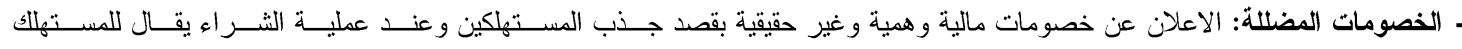

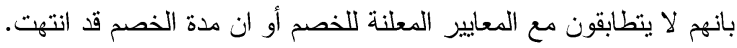

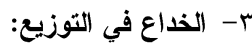

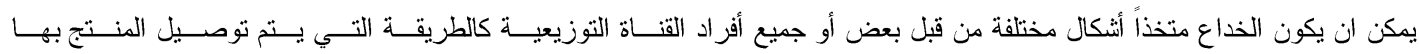

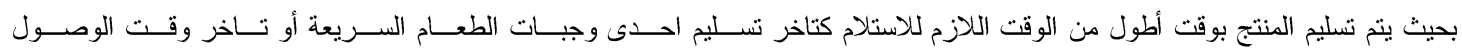

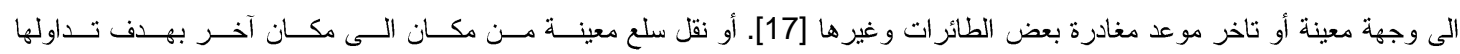
من باب الاحتكار [18].

ع- الخداع في الترويج :ويمكن تقسيم الممارسات الخادعة في التزويج الى ثلاث مجمو عات هي [16]. :

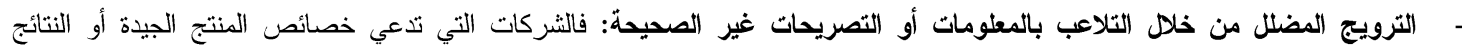
المحتملة بعد الاستعمال و التي ببساطة لا وجود لهال لهاب.

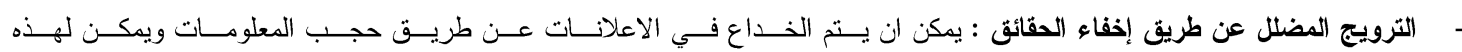
الحقائق ان تعطي انطباعا مضلاًا للمستهلك.

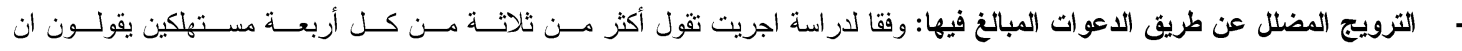

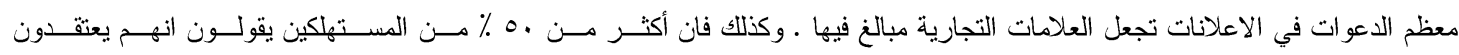

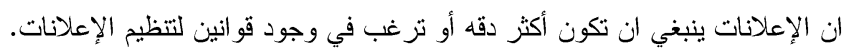

0- الذاع عن طريق مقدمي الخدمة:

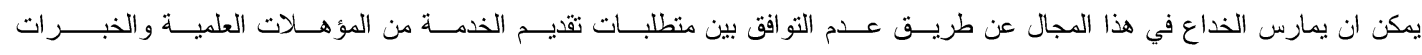

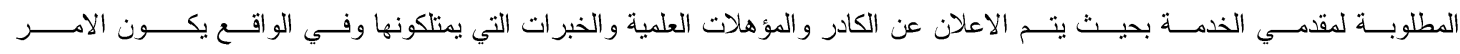

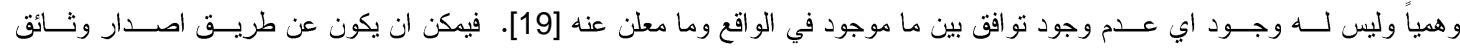

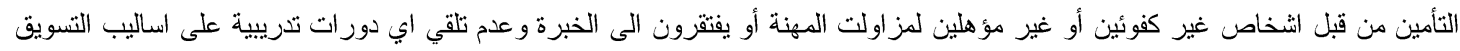
وغيرها من الدورات الضرورية لاكتساب المهارات. أو استعمال اشخاص غير كفو ألئين في نولي المهام الادارية مما يسبب تاخير في انجاز المهام الموكلة اليهم.

؟- الخذاع في مجال عملية تقديم الخدمة

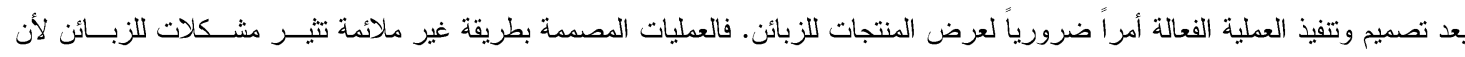

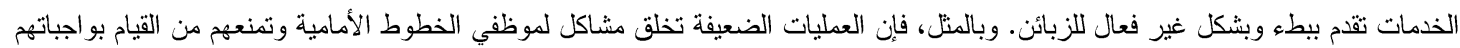

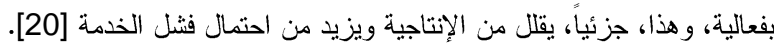

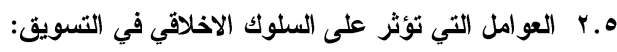

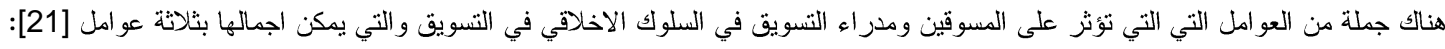

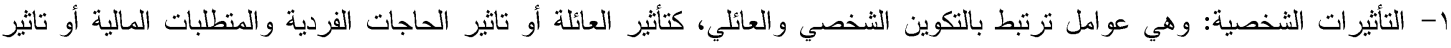

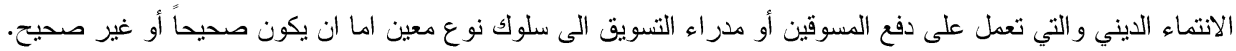

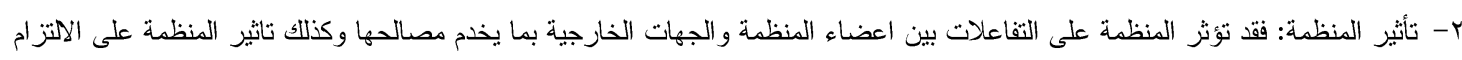

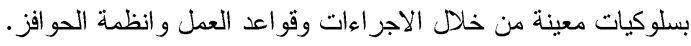

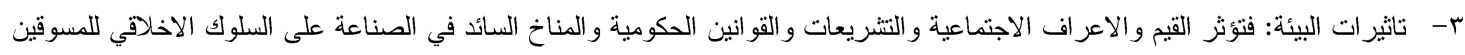
و المدراء. 
Y. Y ب الصورة الذهنية للمنظمة مفهوم الصورة الأنية للمنظمة:

يعرف Plunkett الصورة الذهنية بأنها حدث عقلي ينطوي على تصور لمفهوم أو علاقة، ويمكن اعتبار الصورة الذهنية وسيلة لمعالجـة

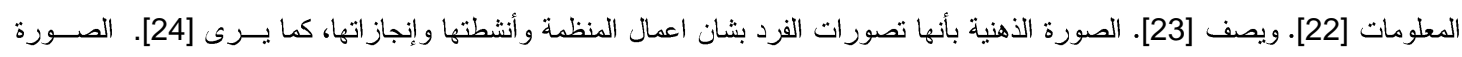

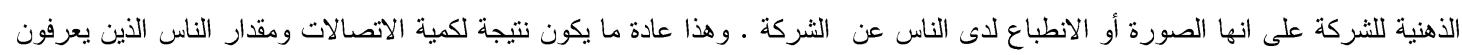

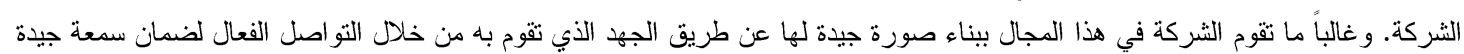
أو اسم جيد للشركة.

كما يعرفها Crompton بانها مجموعة المعتقدات والافكار والانطباعات التي لدى الثخص عن غرض معين [25]. ويعرفها Topalian

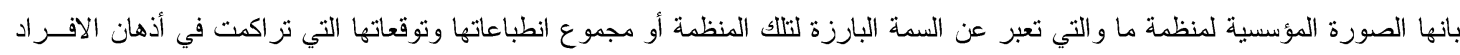

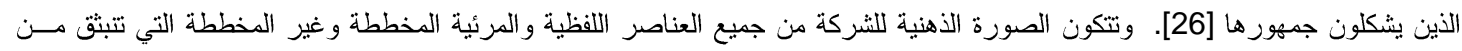
الهيئة الرئيسة للشركة (كيان المؤسسة) ونتزك انطباعاً للمر اقب [27).

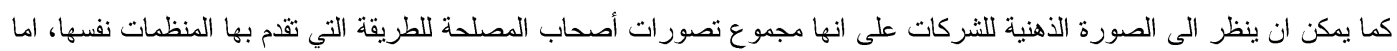
عمداً (مثلا عن طريق أنثطه العلاقات العامة المخطط لها) أو بطريق الخطأ (مثلا من خلال ردود فعل الموظفين أو تعليق وسائل الاعلام) [28].

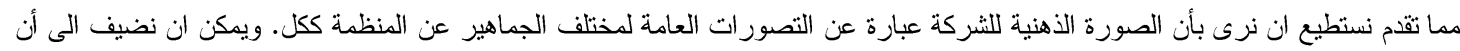
الصورة الذهنية عادةً ما تتتكل بصورة فورية لانى الجماهير المختلفة ، ولذلك يمكن ان ينظر الى الصورة الذهارة الذهية للثركة على انها كل ما يتبادر

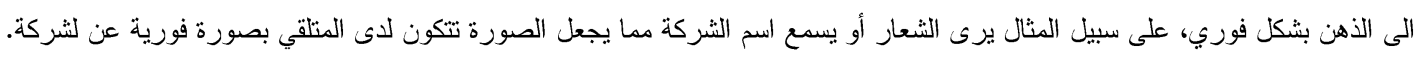

ذوناصر (مكونات) الصورة الأهنية للمنظمة: r.V

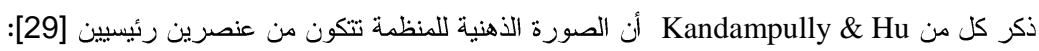
1. المكون الوظيفي : يتعلق العنصر الوظيفي بالخصائص الملموسة التي يمكن قياسها وتقييمها بسهولة، مثل البيئة المادية.

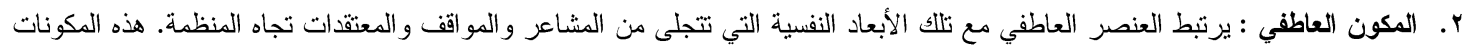

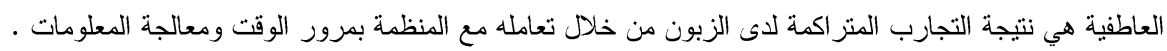
ابعاد الصورة الذهنية: يمكن تقسيم ابعاد الصورة الذهنية للمنظمة الى ثلاثة وكما موضح ادناه :

1- البعد أو المكون المعرفي (الادراكي):

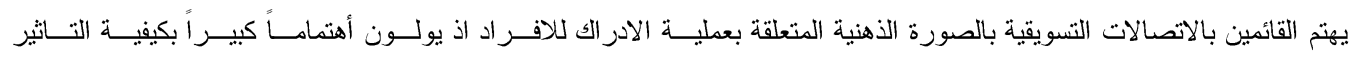

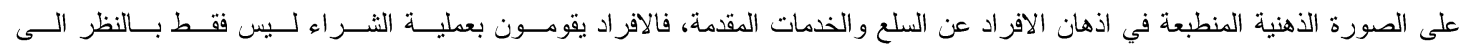

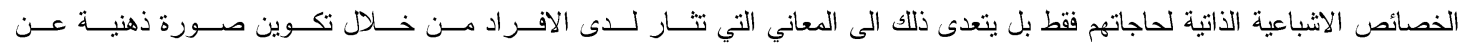

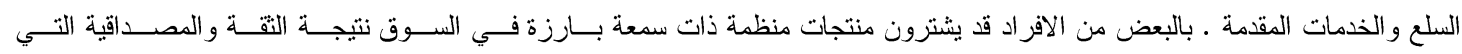

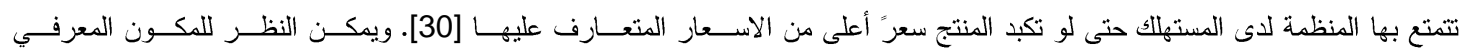

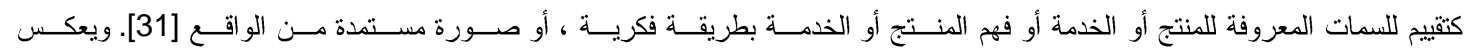

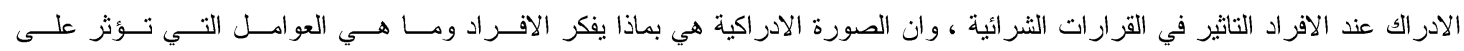

سلوكهم تجاه المنظمة [32].

r - الصورة العاطفية (الوجدانية):

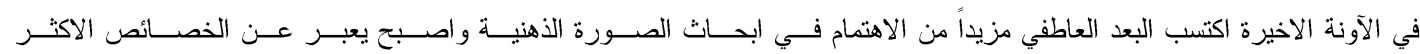

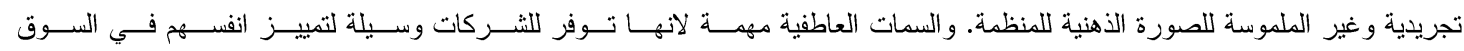

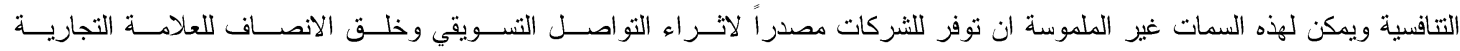

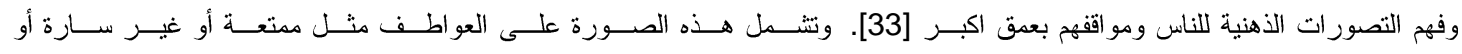

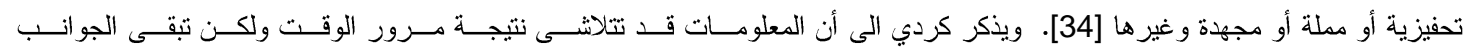

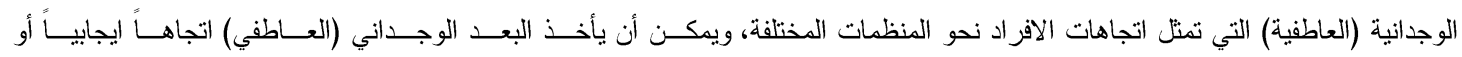

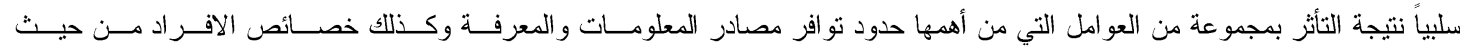

الجنس واللون و اللغة [32]. 


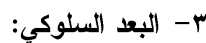

المكون السلوكي هو نزعة سلوكية لفظية أو غير لفظية من قبل الفرد تجاه المنظمة، ويتكون من مجموعة من الأفعال أو الاستجابات التـي

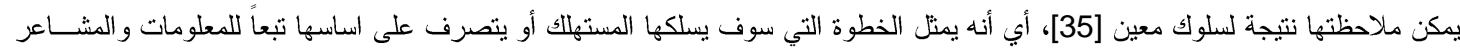

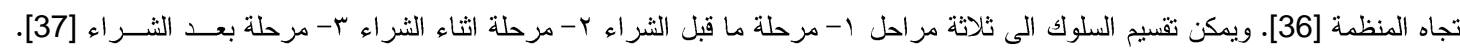

فالبعد السلوكي يعكس طبيعة الصورة الذهنية المشكلة لدى الافر اد في مختلف القضايا وشؤون الحياة [32].

\section{r- الجانب العملي للار اسة}

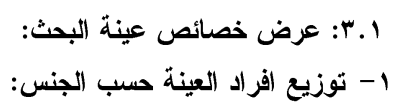

نلاحظ من خلال الجدول (؛) بأن المبحوثين الذين تم اختيارهم بحسب الجنس كانت غير متساوية إذ جاءت النسبة الأعلى إلى الذكور بعدد

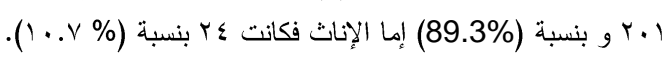

r - توزيع افراد العينة حسب الحالة الاجتماعية :

نلاحظ من خلال الجدول (ع) بأن المبحوثين الذين تم اختيار هم بحسب الحالة الاجتماعية قد بلغت للمتزوجين بنسبة (97.8\%) وهي تمثنل

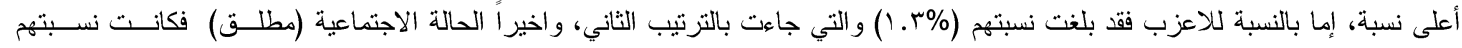

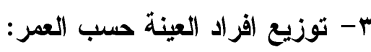

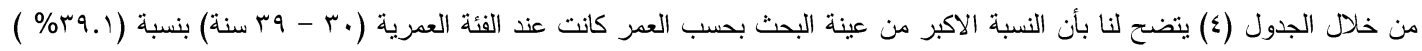

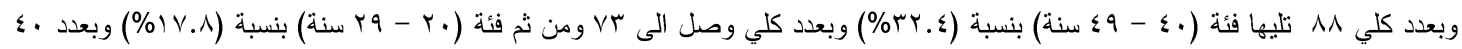

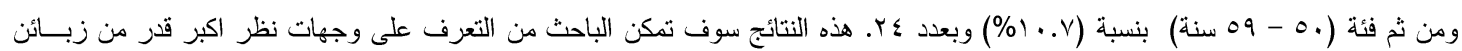
شركات التأمين من خلال التتوع باعمار عينة البحث. ؛ - توزيع افر اد العينة حسب الثهادة:

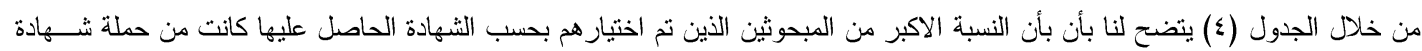

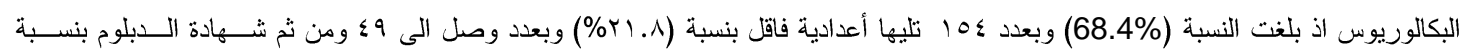

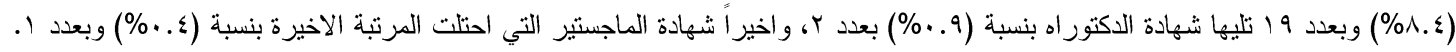

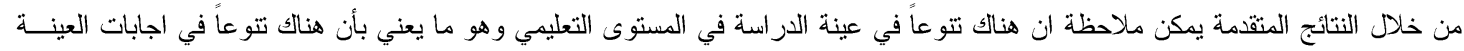
حول موضوع الدراسة مما يضفي عليها طابع المصداقية.

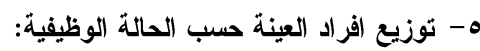

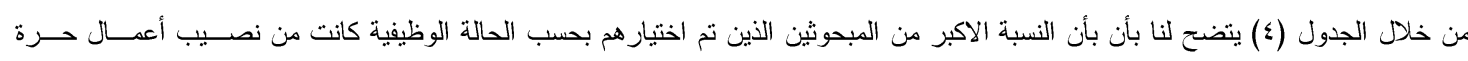

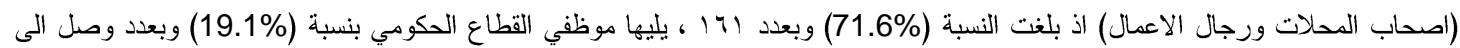

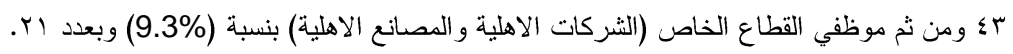
؟- توزيع افر اد العينة حسب مدة التعامل مع شركة التأمين:

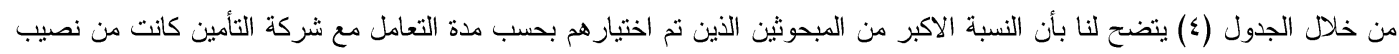

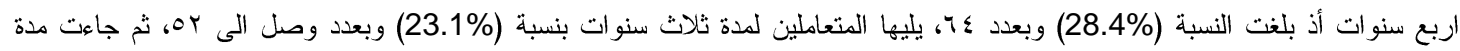

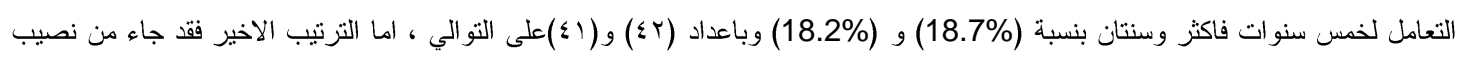

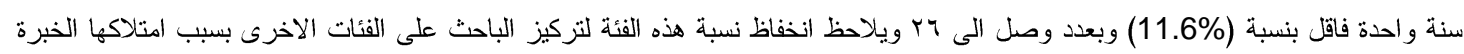
من خلال التعامل مع الثركات المبحوثة أو من خلال الكلام المتناقل عن الثركة. 
جدول (؛) توزيع إفراد العينة حسب الجنس

\begin{tabular}{|c|c|c|c|c|}
\hline حجم العينة & النسبة & التكرار & الخاصية & خصائص عينة البحث \\
\hline \multirow{2}{*}{225} & 89.3 & 201 & ذكر & \multirow{2}{*}{ الجنس } \\
\hline & 10.7 & 24 & انثى & \\
\hline \multirow{3}{*}{225} & 1.3 & 3 & اعزب & \multirow{3}{*}{ الحالة الاجتماعية } \\
\hline & 97.8 & 220 & متزو ج & \\
\hline & 0.9 & 2 & مطلق & \\
\hline \multirow{4}{*}{225} & 17.8 & 40 & سنة 29 - 20 & \multirow{4}{*}{ 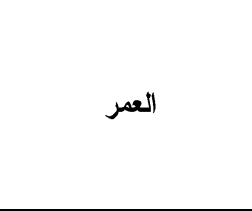 } \\
\hline & 39.1 & 88 & سنة 39 - 30 & \\
\hline & 32.4 & 73 & سنة 49 - 40 & \\
\hline & 10.7 & 24 & سنة 59 - 50 & \\
\hline \multirow{5}{*}{225} & 21.8 & 49 & أعدادية فاقل & \multirow{5}{*}{ الثهادة الحاصل عليها } \\
\hline & 8.4 & 19 & دبلوم & \\
\hline & 68.4 & 154 & بكالوريوس & \\
\hline & 0.4 & 1 & ماجستير & \\
\hline & 0.9 & 2 & دكتور اه & \\
\hline \multirow{3}{*}{225} & 19.1 & 43 & قطاع حكومي & \multirow{3}{*}{ الحالة الوظيفية } \\
\hline & 9.3 & 21 & قطاع خاص & \\
\hline & 71.6 & 161 & أعمال حرة & \\
\hline \multirow{5}{*}{225} & 11.6 & rT & سنة واحدة فاقل & \multirow{5}{*}{ مدة التعامل مع الشركة } \\
\hline & 18.2 & 41 & سنتان & \\
\hline & 23.1 & 52 & تلاث سنو ات & \\
\hline & 28.4 & 64 & اربع سنوات & \\
\hline & 18.7 & 42 & خمس سنو ات فاكثر & \\
\hline
\end{tabular}

المصدر: من اعداد الباحث بالاعتماد على مخرجات نظام SPSS الاصدار ؟ץ

Y.r : عرض وتحليل مستوى أهية متغيرات الاراسة (الاحصاءات الوصفية)

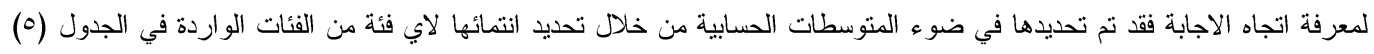

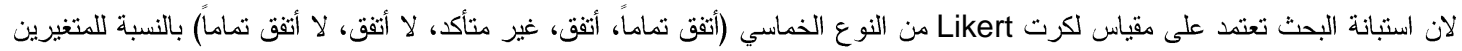
وكما موضح بالفقزات التالية:

جدول (•) معيار المثارنة بين فقرات متغيرات البحث

\begin{tabular}{|c|c|c|}
\hline مستوى الاجابة & طول الفئة & $ت$ \\
\hline ضعيف جداً & $1.89-1 \ldots$ & 1 \\
\hline ضعيف & r.09-1.1. & r \\
\hline متوسط & r.rq - r.t. & $r$ \\
\hline جيد & $\varepsilon .19-$ r.s. & $\varepsilon$ \\
\hline جيد جداً & $0 . \ldots-\varepsilon . r$. & 0 \\
\hline
\end{tabular}

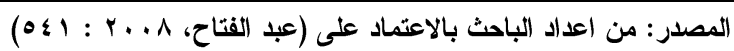


أولاً : محور ممارسات الخداع التسويقي

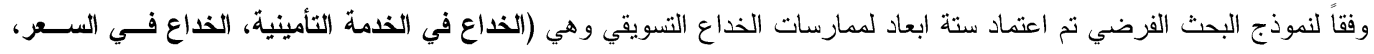

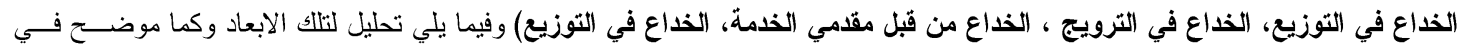
الفقرات التالية :

1. الخداع في الخدمة التأمينية:

يظهز من الجدول (آ) الوسط الحسابي والانحر اف المعياري ومتوسط الوزن النسبي وترتيب الاهمية بالنسبة للفقرات وكذلك اتجاه الاجابة

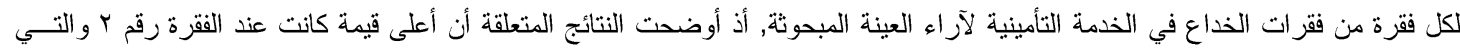

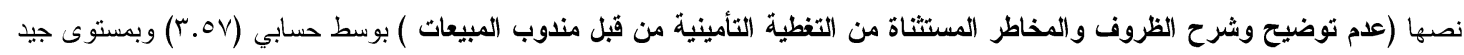

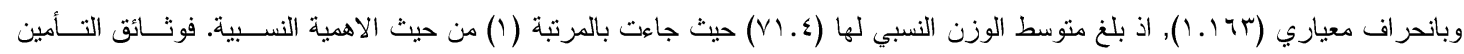

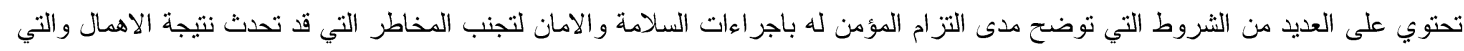

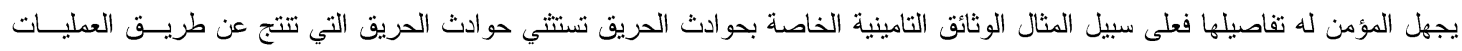

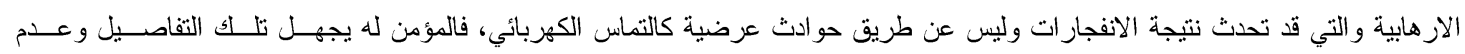

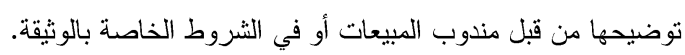

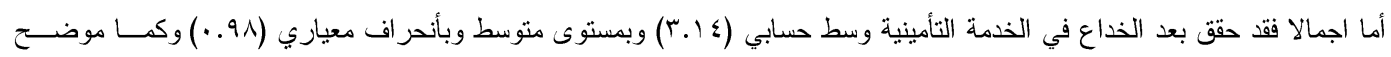

بالجدول (†).

جدول (؟) الوسط الحسابي و الاحمراف المعياري لأجابات العينة المبحوثة حول الذذاع في الخدمة التأمينية

\begin{tabular}{|c|c|c|c|c|c|c|}
\hline مستوى & ترتيب الاهمية & الوزن النسبي & 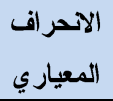 & المتوسط الحسابي & 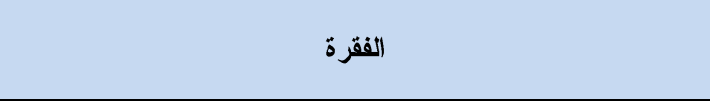 & (الفقرة \\
\hline 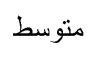 & 3 & 65.60 & 1.22 & 3.28 & تحتوي وثيقة التأمين عبار ات ومصطلحات فنية تتسم بالغموض & 1 \\
\hline جيد & 1 & 71.47 & 1.16 & 3.57 & من قدم توضيح وشر ح الظروف و المخاطر المستثاة من التغطية التأمينية & r \\
\hline منوسط & 6 & 52.71 & 1.14 & 2.64 & تستخدم الثركة عبارات مطبو عة بشكل صغير للتمويه أو إخفاء بعض المتعل بموضو التمين & $r$ \\
\hline منوسط & 5 & 58.04 & 1.05 & 2.90 & تقلل الثركة من معلومات سياسة الانساب من وثيقة التأمين & $\varepsilon$ \\
\hline 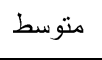 & 2 & 66.31 & 1.17 & 3.32 & عدم متابعة التغير ات التي تطر أ على موضوع التأمين من قبل الثركة & ० \\
\hline 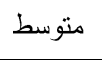 & 4 & 62.67 & 1.28 & 3.13 & تعمد أدارة الثركة الى ابقاء فقرة الغرامات غامضة & 7 \\
\hline منوسط & & & 0.98 & 3.14 & المتوسط الحسابي و الانحر اف المعياري للبعد & \\
\hline
\end{tabular}

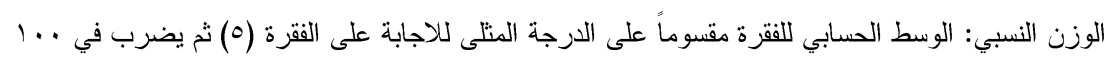

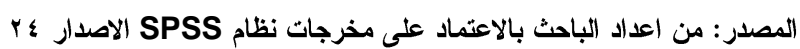

أوضحت النتائج المتعلقة ببعد الذداع في السعر أن أعلى قيمة كانت عند الفقرة رقم ال او التي نصها (عدم تقايم تسهيلات لتسديد ثــط

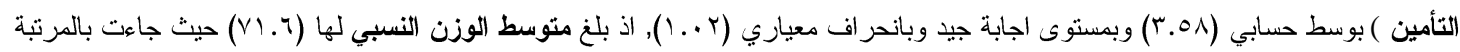

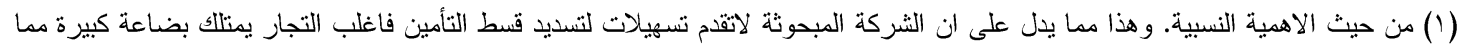

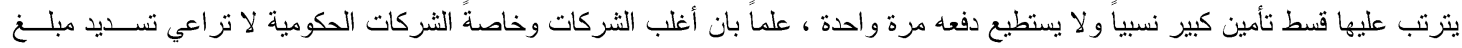
القسط على شكل دفعات متعددة.

أما اجمالا فقد حقق الخداع في السعر وسط حسابي (V) (V) وبمستوى متوسط وبأندر اف معياري (0.89) وكما موضح بالجدول (V) 
جدول (V) الوسط الحسابي والاحرراف المعياري لأجابات العينة المبحوثة حول الذاع في السعر

\begin{tabular}{|c|c|c|c|c|c|c|}
\hline مستوى الاجابة & ترتيب الاهمية & الوزن النسبي & الالمعياري & المتوسط الحسابي & 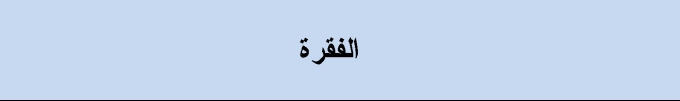 & الفقرة \\
\hline متوسط & 5 & 56.62 & 1.18 & 2.83 & عدم أخبار المؤمن له عن المصاريف التي يتحملها في وثيقة التأمين & $\checkmark$ \\
\hline متوسط & 4 & 60.80 & 1.09 & 3.04 & التأمين توضيح المصاريف الاخرى التي تستمر مع استمر ارية وثيقة & $\wedge$ \\
\hline متوسط & 3 & 63.38 & 1.00 & 3.17 & تاخرض الشركة اقساط عالية على وثائق التأمين مقارنتأ مع الشركات & 9 \\
\hline متوسط & 2 & 64.18 & 1.08 & 3.21 & تسعير وثائق التأمين مبهمة وغامضة & 1. \\
\hline جيد & 1 & 71.64 & 1.02 & 3.58 & عدم تقديم تسهيلات لتسديد قسط التأمين & 11 \\
\hline متوسط & & & 0.89 & 3.17 & ت عسابي و الانحر اف المعياري للبعد & المتوسط \\
\hline
\end{tabular}

المصدر: من اعداد الباحث بالاعتماد على مخرجات نظام SPSS الاصدار ؛

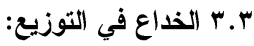

بينت النتائج المتعلقة بالخداع في التوزيع أن أعلى قيمة كانت عند الفقرة 17 والتي نصها (يتطلب الوصول الى الثركة الكثير من الجها

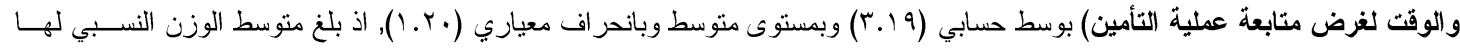

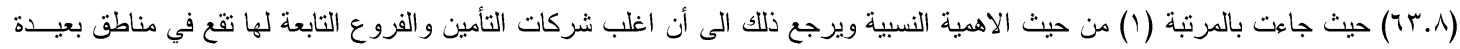

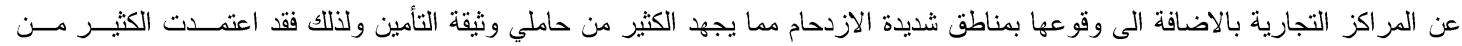

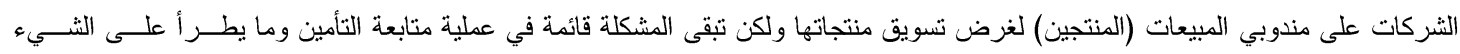

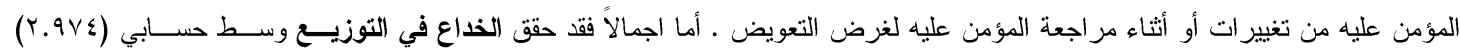

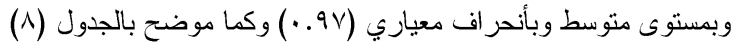

جدول (^) الوسط الحسابي والاحر اف المعياري لأجابات العينة المبحوثة حول الذداع في التوزيع

\begin{tabular}{|c|c|c|c|c|c|c|}
\hline مستوى & ترتيب الاهمية & الوزن النسبي & الالمحر اف المعياري & المتوسط الحسابي & 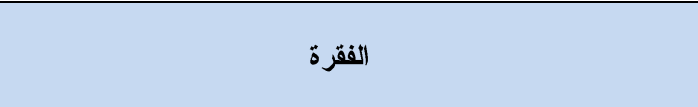 & الفقرة \\
\hline ضعيف & 5 & 49.51 & 1.27 & 2.48 & المؤمن لهر الثركة من خلال مندوبي المبيعات شبكة اتصال جيدة مع & ir \\
\hline متوسط & 2 & 63.64 & 1.13 & 3.18 & يمكن للزبون الاتصال بالثركة عبر موقعها الالكتروني & ir \\
\hline متوسط & 3 & 61.60 & 1.07 & 3.08 & توفر الثركة معلومات كافية عن نفسها وخدماتها من خلال موقعها & $1 \leqslant$ \\
\hline متوسط & 4 & 58.76 & 1.10 & 2.94 & تمتلك الثركة العديد من الفروع و المكاتب لتقديم خدماتها للزبائن & 10 \\
\hline متوسط & 1 & 63.82 & 1.20 & 3.19 & عملية التأمين الوصول الى الشركة الكثير من الجهد والوقت لغرض متابعة & 17 \\
\hline متوسط & & & 0.97 & 2.97 & حسابي والانحر اف المعياري اللبعد & 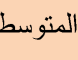 \\
\hline
\end{tabular}

المصدر : من اعداد الباحث بالاعتماد على مخرجات نظام SPSS الاصدار ؟ץ 


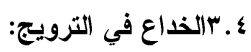

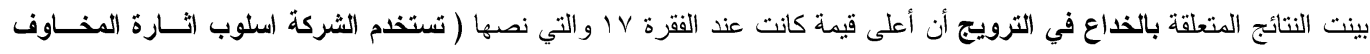

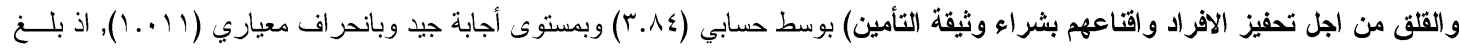

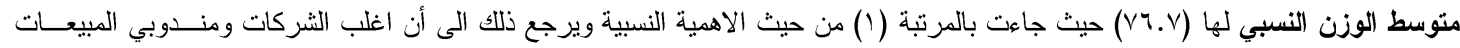

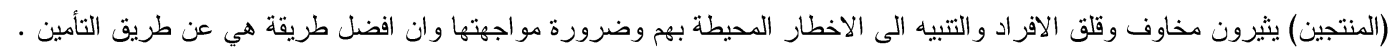

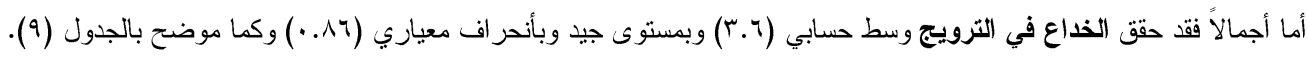

جدول (9) الوسط الحسابي والآحر اف المعياري لأجابات العينة المبحوثة حول الخداع في الترويج

\begin{tabular}{|c|c|c|c|c|c|c|}
\hline مستوى & ترتيب الاهمية & 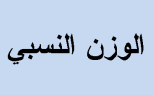 & 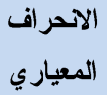 & المتوسط الحسابي & 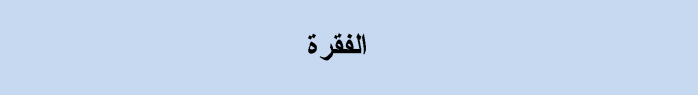 & 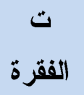 \\
\hline جيد & 1 & 76.71 & 1.01 & 3.84 & و تقتخدم الثركة اسلوب اثارة المخاوف و القلق من اجل تحفيز الافراد & iv \\
\hline جيد & 3 & 72.27 & 1.05 & 3.61 & 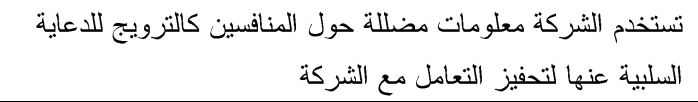 & 11 \\
\hline جيد & 5 & 68.89 & 0.98 & 3.44 & تروج الثركة لبعض الخدمات لكي تبدو متميزة عن الثركات & 19 \\
\hline جيد & 4 & 69.42 & 1.06 & 3.47 & تعلن الثركة عن هدايا ترويجية لتشجيع عملية شراء وثائق التأمين & r. \\
\hline جيذ & 2 & 72.89 & 1.16 & 3.64 & يبالغ موقع الشركة الإلكتروني في الفو ائد المحتملة من عملية التأمين & r) \\
\hline جيد & & & 0.86 & 3.60 & \multicolumn{2}{|c|}{ المتوسط الحسابي و الانحر اف المعياري للبعد } \\
\hline
\end{tabular}

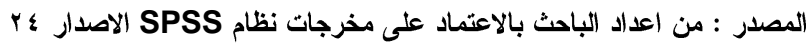

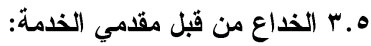

بينت النتائج المتعلقة بالخداع من قبل مقامي الخدمة أن أعلى قيمة كانت عند الفقرة بr و التي نصها (يرسم مندوب المبيعات صور جيدة

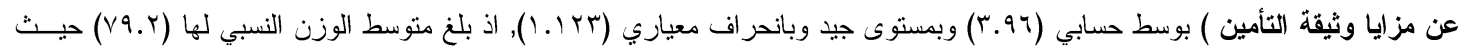

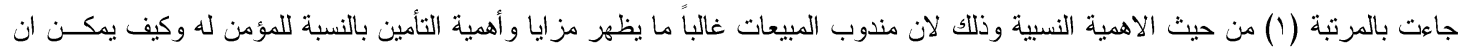
يو اجه اخطار من المحتمل حدوثها عن طريق التأمين.

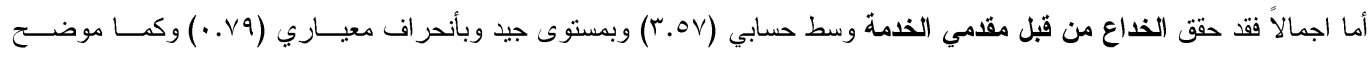

بالجدول (·) (1).

جدول ( 1) الوسط الحسابي والاحمر اف المعياري لأجابات العينة المبحوثة حول الذاع من ثبل مقدمي الخدمة

\begin{tabular}{|c|c|c|c|c|c|c|}
\hline مستوى & ترتيب الاهمية & الوزن النسبي & 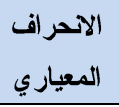 & المتوسط الحسابي & 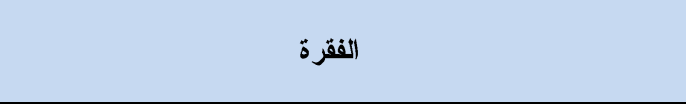 & 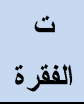 \\
\hline جيد & 2 & 76.36 & 1.13 & 3.82 & يلجأ مندوب المبيعات للتضليل في المعلومات من اجل جذب الزبائن & rt \\
\hline متوسط & 4 & 65.33 & 0.73 & 3.27 & 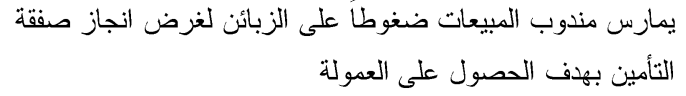 & rr \\
\hline جيد & 3 & 72.98 & 0.95 & 3.65 & عدم قدرة مندوب المبيعات على فهم أحتياجات الزبائن من أنواع & $r \varepsilon$ \\
\hline جيد & 1 & 79.20 & 1.12 & 3.96 & يرسم مندوب المبيعات صور جيدة عن مز ايا وثيقة التأمين & ro \\
\hline متوسط & 5 & 63.11 & 1.18 & 3.16 & 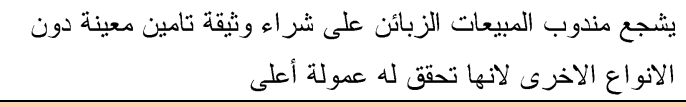 & YY \\
\hline جيد & & & 0.79 & 3.57 & ل لحسابي و الانحر اف المعياري للبعد & 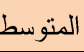 \\
\hline
\end{tabular}

المصدر : من اعداد الباحث بالاعنماد على مخرجات نظام SPSS الاصدار ؟ 


\section{צ. T الخداع في عملية تقليم الخدمة:}

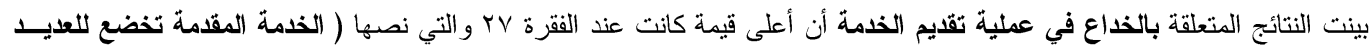

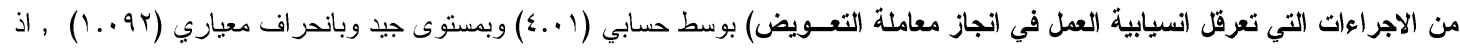

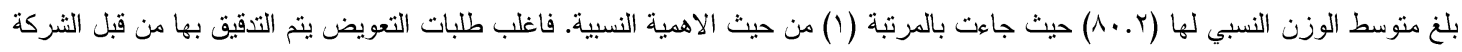

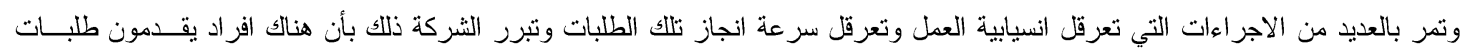

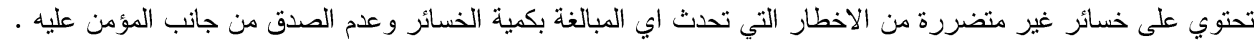

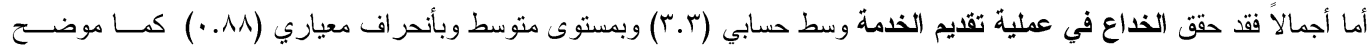

بالجدول (11).

جدول (11) الوسط الحسابي والاحمراف المعياري لأجابات العينة المبحوثة حول الخداع في عملية تقديم الخذمة

\begin{tabular}{|c|c|c|c|c|c|c|}
\hline الاجابة & ترتيب الاهمية & الوزن النسبي & المعياري & المتوسط الحسابي & 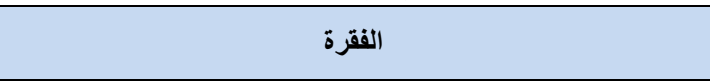 & الفقرة \\
\hline جيد & 1 & 80.27 & 1.09 & 4.01 & العمل في انجاز معاملة التعويضة تخضع للعديد من الاجر اءات التي تعرقل انسيابية & $T V$ \\
\hline متوسط & 4 & 62.93 & 1.13 & 3.15 & التأمين و اعتمادهم منذوبي المبيعات من احتساب القيمة الحقيقية لموضوع & r^ \\
\hline متوسط & 2 & 64.98 & 0.97 & 3.25 & التفصيلية لوثنقة التاحسى من قبل الثركة او مندوب المبىعات عن المكونات & rq \\
\hline متوسط & 5 & 57.16 & 1.14 & 2.86 & 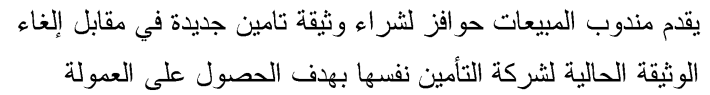 & $r$. \\
\hline متوسط & 3 & 64.53 & 1.15 & 3.23 & تو افر الاهتمام في من قبل شركة التأمين بمنطلبات الحماية والامان الو اجب & $\mu_{1}$ \\
\hline منوسط & & & 0.88 & 3.30 & \multicolumn{2}{|c|}{ المتوسط الحسابي والانحر اف المعياري للبعد } \\
\hline
\end{tabular}

المصدر : من اعداد الباحث بالاعتماد على مخرجات نظام SPSS الاصدار ع ؟

V. V. المتوسط الحسابي والاحصر اف المعياري وترتيب الاهمية لأبعاد متغير الخداع التسويقي :

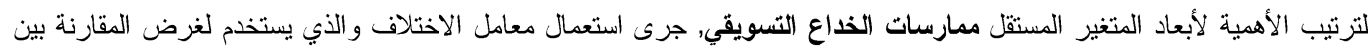

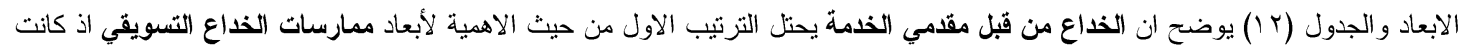

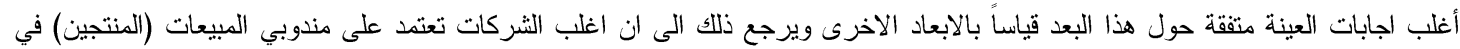

عملية تسويق منتجاتها.

جدول ( ا ) ترتيب الاهمية بالاعتماد على معامل الاختلاف لأبعاد ممارسات الخداع التسويقي

\begin{tabular}{|c|c|c|c|c|c|}
\hline ترتيب الاهمية & الاختلاف معامل & الالمعراف & الحسابي & 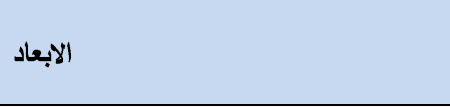 & $\begin{array}{c}\text { البعد } \\
\end{array}$ \\
\hline 5 & 31.210 & 0.98 & 3.14 & الخداع في الخدمة التأمينية & 1 \\
\hline 4 & 28.076 & 0.89 & 3.17 & الخداع في السعر & r \\
\hline 6 & 32.660 & 0.97 & 2.97 & الخداع في التوزيع & r \\
\hline 2 & 23.889 & 0.86 & 3.60 & الخداع في الترويج & $\varepsilon$ \\
\hline 1 & 22.129 & 0.79 & 3.57 & الخداع من قبل مقدمي الخدمة & o \\
\hline 3 & 26.667 & 0.88 & 3.30 & الخداع في عملية تقديم الخدمة & 1 \\
\hline & & 0.83 & 3.29 & \multicolumn{2}{|c|}{ المتوسط الحسابي و الانحر اف المعياري للمتغير } \\
\hline
\end{tabular}

المصدر : من اعداد الباحث بالاعتماد على مخرجات نظام SPSS الاصدار ؟Y 
ثانياً: محور الصورة الذهنية

وفقاً لنموذج البحث الفرضورة الفي تم اعتماد ثلاثة ابعاد للصورة الذهنية وهي (البعد المعرفي (الادراكي)، البعد العاطفي (الوجــاني)، البعـــ

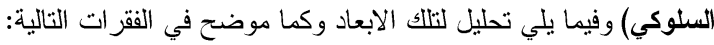

ا بـ البعد المعرفي (الادر اكي):

يظهر من الجدول (13) بأن الوسط الحسابي و الانحر اف المعياري ومتوسط الوزن النسبي وترتيب الاهمية بالنسبة للفقرات وكذلك اتجــاه

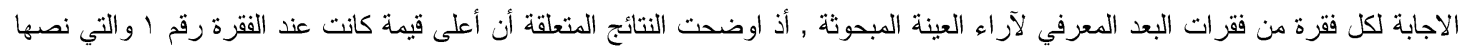

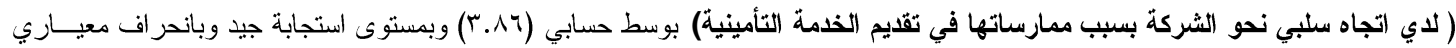

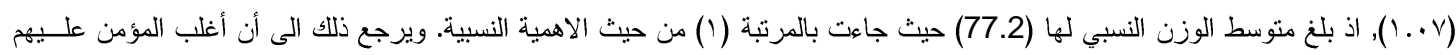

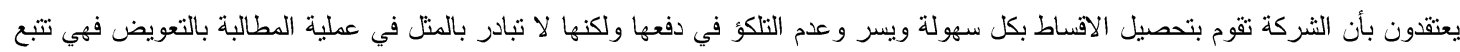

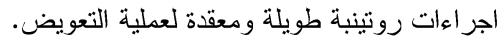

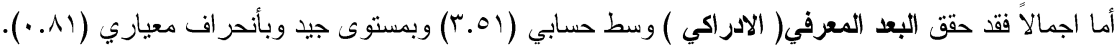

جدول (r ا ) الوسط الحسابي والاححر اف المعياري لأجابات العينة المبحوثة حول البعد المعرفي ( الادراكي )

\begin{tabular}{|c|c|c|c|c|c|c|}
\hline مستوى & ترتيب الاهمية & 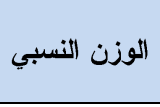 & 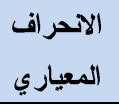 & المتوسط الحسابي & 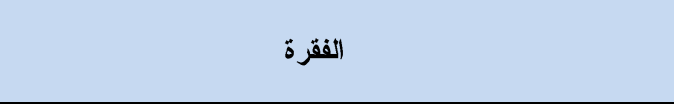 & 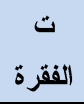 \\
\hline 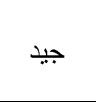 & 1 & 77.24 & 1.07 & 3.86 & التأمينية اتجاه سلبي نحو الشركة بسبب ممارساتها في تقديم الخدمة & 1 \\
\hline جيد & 3 & 69.33 & 0.81 & 3.47 & تتحمل شركة التأمين مسؤوليتها الاجتماعية تجاه المجتمع & r \\
\hline 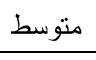 & 6 & 65.96 & 1.06 & 3.30 & عدم الحصول على فائدة عالية من الخدمة التأمينية & r \\
\hline جيد & 5 & 67.73 & 0.99 & 3.39 & تتهرب الثركة عن دفع المستحقات المترتبة عليها الى المؤمن لله & $\varepsilon$ \\
\hline جيد & 4 & 68.89 & 0.97 & 3.44 & تحاول شركة التأمين بيع وثيقة التأمين باي طريقة كانت & $\circ$ \\
\hline جيد & 2 & 72.62 & 1.11 & 3.63 & غالتأمياً ما يحصل المؤمن له على تعويض اقل مما يتوقعه نهاية مدة & ч \\
\hline جيد & & & 0.81 & 3.51 & \multicolumn{2}{|c|}{ لمتوسط الحسابي و الانحر اف المعياري للبعد } \\
\hline
\end{tabular}

المصدر: من اعداد الباحث بالاعتماد على مخرجات نظام SPSS الاصدار ؟

r r البعد العاطقي (الوجداني):

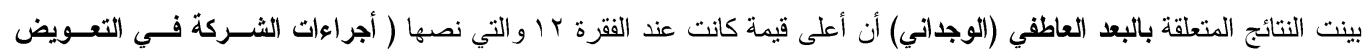

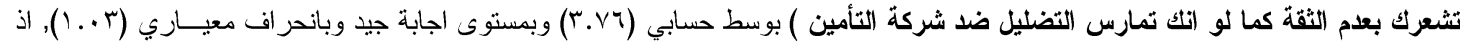

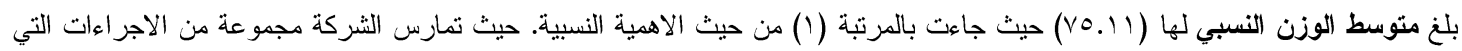

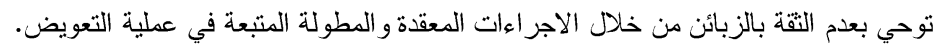

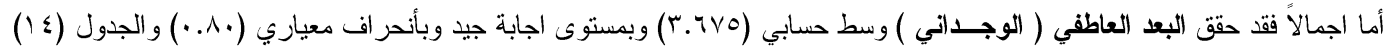

جدول (ع ا) الوسط الحسابي والاحر اف المعياري لأجابات العينة المبحوثة حول البعد العاطفي (الوجداني)

\begin{tabular}{|c|c|c|c|c|c|c|}
\hline مستوى & ترتيب الاهمية & المزن النسبي & 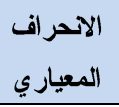 & المتوسط الحسابي & 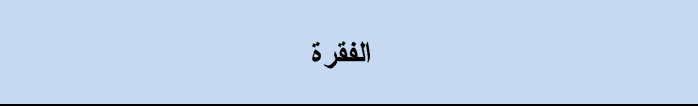 & 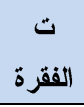 \\
\hline 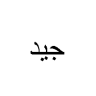 & 2 & 74.4 & 1.15 & 3.72 & شتركة ( الصدق افضل سياسة ) غير متبع من قبل مندوبي المبيعات & v \\
\hline جيد & 4 & 72.8 & 0.93 & 3.64 & اشعر أن الشركة غير محفزة للمستقيدين من خدماتها & $\wedge$ \\
\hline جيد & 5 & 72.4 & 0.98 & 3.62 & تساهم شركة التأمين في توليد الثعور بالامان و الحماية & 9 \\
\hline جيد & 6 & 72.4 & 1.06 & 3.62 & تقتي ضعيفة في ادعاءآت (وعود ) شركة التأمين & 1. \\
\hline جيد & 3 & 73.8 & 1.06 & 3.69 & عند مشاهدتي لشعار الشركة أو اسمها اثشعر بالسلبية تجاهها & 11 \\
\hline 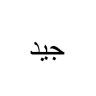 & 1 & 75.2 & 1.03 & 3.76 & التضليل ضداء الشركة في التعويض تشعرك بعدم التقة كما لو انك تمارس & ir \\
\hline جيد & & & 0.80 & 3.67 & \multicolumn{2}{|c|}{ المتوسط الحسابي والانحر اف المعياري للبعد } \\
\hline
\end{tabular}


المصدر: من اعداد الباحث بالاعتماد على مخرجات نظام SPSS الاصدار ؟ ؟

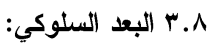

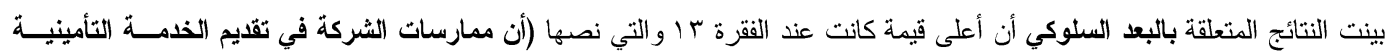

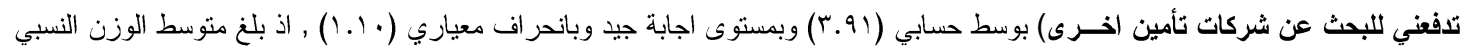

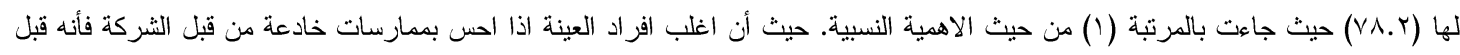

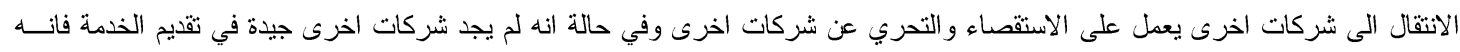

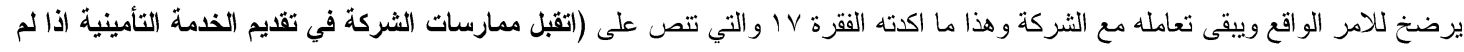

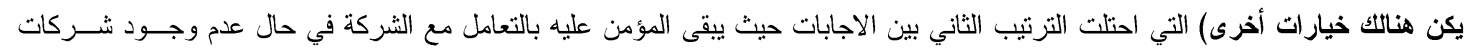
اخرى ذات جودة عالية في تقديم الخدمة. أما أجمالاً فقد حقق البعد السلوكي وسط حسابي (ع \.ب) وبمستوى جيد وبأندراف معياري (19. · ) وكما موشح بالجدول (10).

جدول (0) الوسط الحسابي و الاحر اف المعياري لأجابات العينة المبحوثة حول البعد السلوكي

\begin{tabular}{|c|c|c|c|c|c|c|}
\hline مستوى & ترتيب الاهمية & الوزن النسبي & 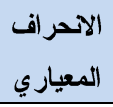 & المتوسط الحسابي & 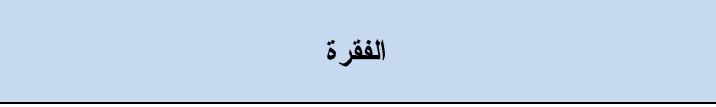 & (الفقرة \\
\hline جيد & 1 & 78.2 & 1.10 & 3.91 & شركات تأمين اخرى ممات الثركة في تقديم الخدمة التأمينية تدفعني للبحث عن & ir \\
\hline جيد & 4 & 72.8 & 0.98 & 3.64 & 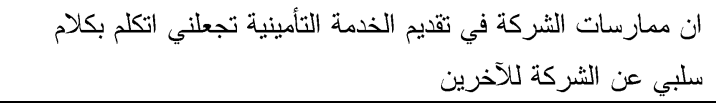 & $1 \leqslant$ \\
\hline 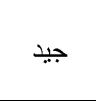 & 3 & 74.6 & 1.07 & 3.73 & بالتعامل مع الثركة الثركة في تقديم الخدمة التأمينية تدفعني بعدم الاستمرار & 10 \\
\hline جيد & 5 & 72.6 & 1.14 & 3.63 & مع الثركة ممارسات الثركة في تقديم الخدمة التأمينية تدفعني للحذر بالتعامل & 17 \\
\hline جيد & 2 & 75.8 & 1.08 & 3.79 & خيار ات أخرى ممارسات الثركة في تقديم الخدمة التأمينية اذا لم يكن هنالك & iv \\
\hline جيد & & & 0.89 & 3.74 & \multicolumn{2}{|c|}{ المتوسط الحسابي والانحر اف المعياري للبعد } \\
\hline
\end{tabular}

المصدر : من اعداد الباحث بالاعتماد على مخرجات نظام SPSS الاصدار \&ץ

9. المتوسط الحسابي والاتحر اف المعياري وترتيب الاهمية لأبعاد متغير الصورة الذهنية:

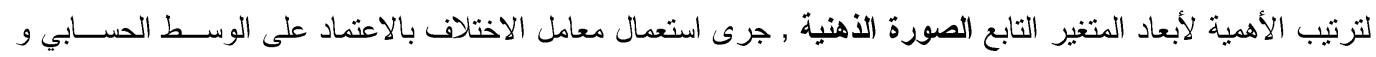
الانحر اف المعياري و الجدول (7 1) يوضح ان الصورة الأهنية العاطفية (الوجدانية) بحتل التزتيب الاول من حيث أبعاد الصورة الذهنية اذ كانت أغلب اجابات العينة متفقة حول هذا البعد قياساً بالابعاد الاخرى.

جدول (7 1 ) ترتيب الاهمية بالاعتماد على معامل الاختلاف لأبعاد الصورة الذهنية للمنظمة

\begin{tabular}{|c|c|c|c|c|c|}
\hline ترتيب الاهمية & الاختلاف معلف & المعياري & الحسابي & 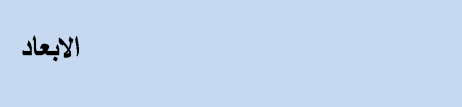 & البعد \\
\hline 2 & 23.077 & 0.81 & 3.51 & البعد المعرفي (الادراكي) & 1 \\
\hline 1 & 21.798 & 0.80 & 3.67 & البعد العاطفي (الوجداني) & r \\
\hline 3 & 23.797 & 0.89 & 3.74 & البعد السلوكي & $r$ \\
\hline & & 0.80 & 3.64 & \multicolumn{2}{|c|}{ المتوسط الحسابي والانحر اف المعياري للمتغير } \\
\hline
\end{tabular}

المصدر : من اعداد الباحث بالاعتماد على مخرجات نظام SPSS الاصدار ؟؟ 
ثالثاً :أختبار وتحليل فرضيات علاقة الارتباط بين متغيرات الاراسة:

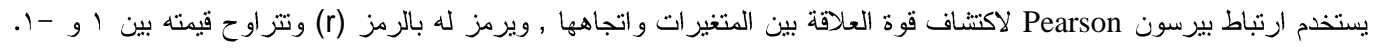

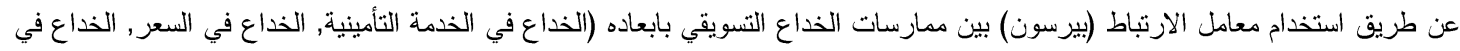

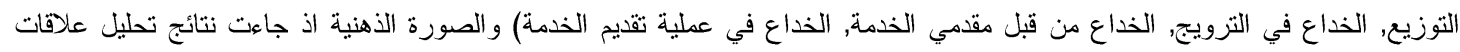

الارتباط كما في الجدول (IV)

جدول (IV) علاقات الارتباط بين متغير ات الادراسة

\begin{tabular}{|c|c|c|c|c|c|c|c|}
\hline ممارسـات الخداع & علية تقديم الخداع في & قالخد مقدمي من & التذاع في & التذاع في & الخداع في & الخداع في التأمينة & أبعاد ممارسات التداع التسويقي \\
\hline $0.711 * *$ & $0.741 * *$ & $0.641 * *$ & $0.671 * *$ & $0.721 * *$ & $0.764 * *$ & $0.694 * *$ & الصورة الذهنية \\
\hline 5.595 & 6.135 & 4.888 & 4.889 & 5.784 & 6.605 & 5.295 & قيمة (t) \\
\hline
\end{tabular}

**(Correlation is significant at the 0.01 level (2-tailed).

$$
\text { حجم العينة (n) }
$$

اختبار الفرضية الرئيسية الاولى:

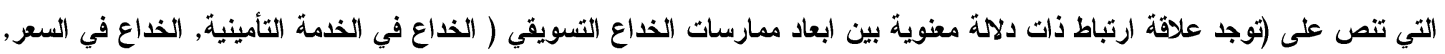

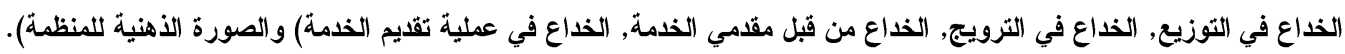

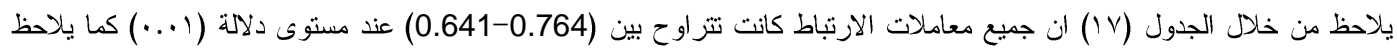

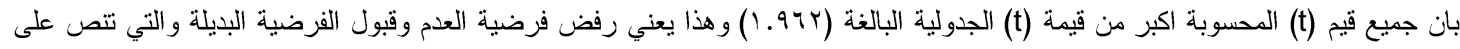

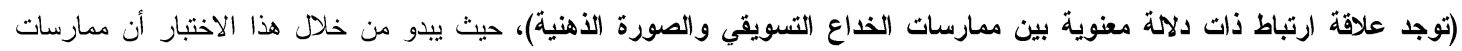

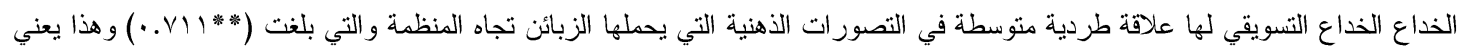
انه كلما زاد استعمال الممارسات التسويقية الخادعة و المضللة كلما زادت الصورة لفئه الذهنية السلبية تجاه المنظمة.

رابعاً : أختبار وتحليل فرضيات التأثير بين متغير ات الدراسة:

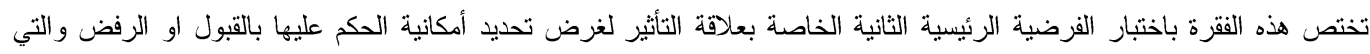

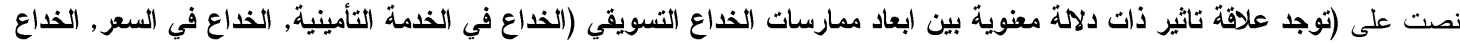

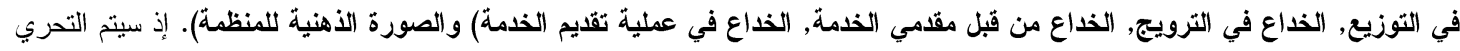

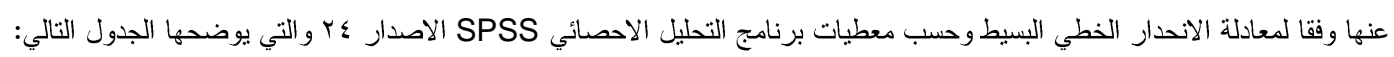

جدول (1/) تحليل ابعاد ممارسات الذاع التسويقي في الصورة الذهنية

\begin{tabular}{|c|c|c|c|c|c|c|c|c|}
\hline الدالة & Sig & قالجدة (F) قيمة & قالمسة (F) & $\begin{array}{l}\text { معامل } \\
\text { التحديد } \\
\left(\mathbf{R}^{2}\right)\end{array}$ & 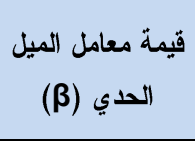 & قابثة الحد & المتغير & إبعاد ممارسات الخداع التسويقي \\
\hline 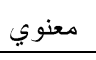 & 0.000 & \multirow{7}{*}{5.10} & 28.038 & 0.482 & 0.276 & 2.755 & \multirow{7}{*}{ 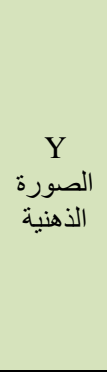 } & الذداع في الخدمة التأمينية \\
\hline 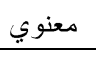 & 0.000 & & 43.623 & 0.584 & 0.361 & 2.465 & & الخداع في السعر \\
\hline معنوي & 0.000 & & 33.453 & 0.520 & 0.301 & 2.672 & & الخداع في التوزيع \\
\hline 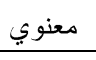 & 0.000 & & 23.899 & 0.450 & 0.269 & 2.733 & & الخداع في الترويج \\
\hline معنوي & 0.000 & & 19.134 & 0.411 & 0.257 & 2.753 & & الخداع من قبل مقدمي الخدمة \\
\hline معنوي & 0.000 & & 37.856 & 0.549 & 0.359 & 2.432 & & الخداع في عملية تقديم الخدمة \\
\hline معنوي & 0.000 & & 31.303 & 0.506 & 0.354 & 2.475 & & ممارسات الذداع التسويقي \\
\hline
\end{tabular}

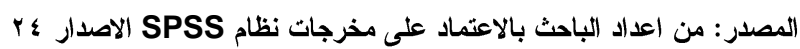

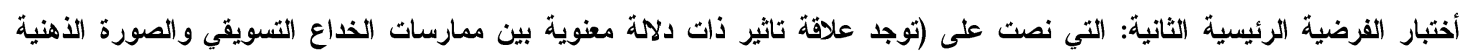

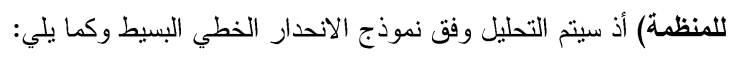


فطبقاً لمعطيات الجدول (1) يمكن ان نوضح التالي:

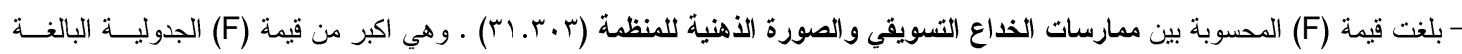

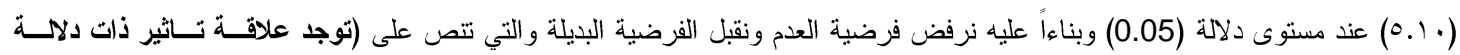

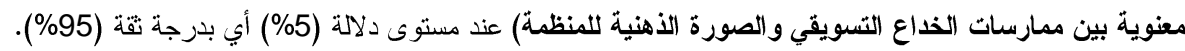

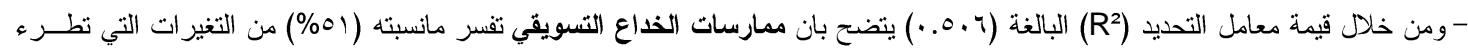
على الصورة الأهنية.

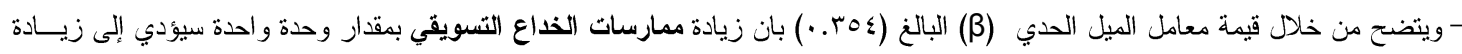

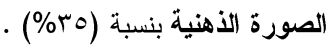

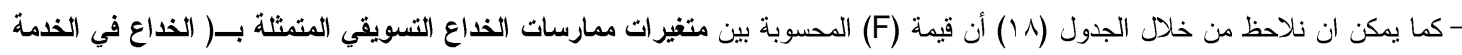

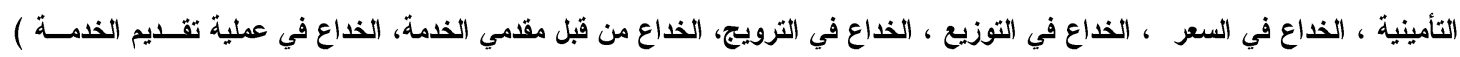

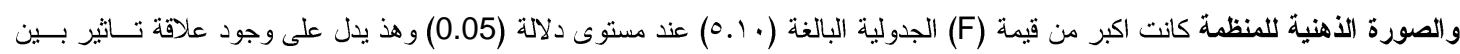

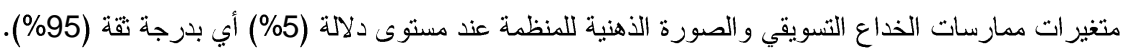

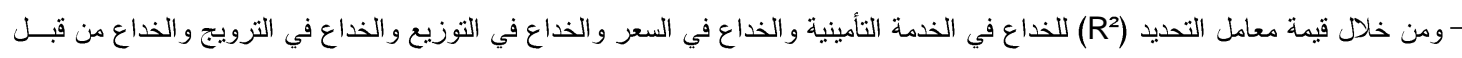

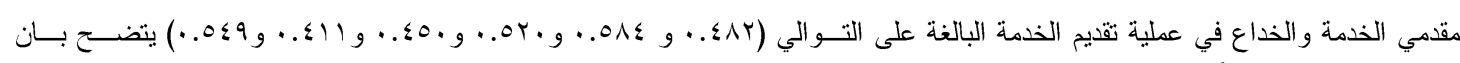

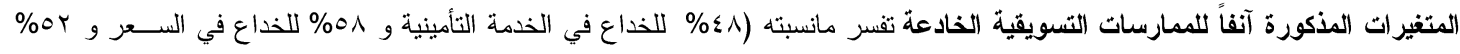

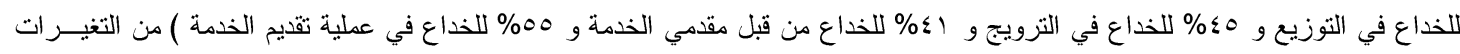

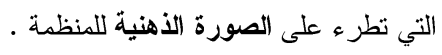

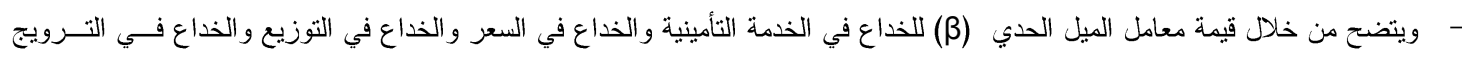

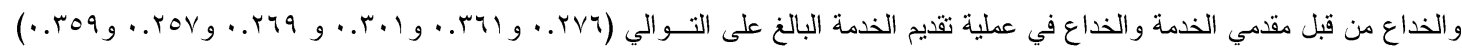

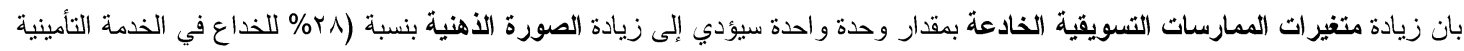

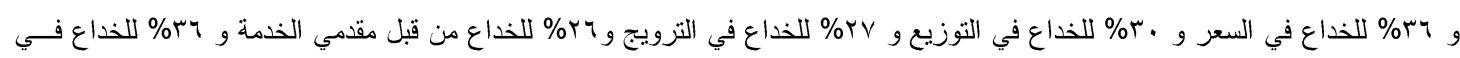
عملية تقديم الخدمة).

\section{ع - - الاستنتاجات و التوصيات}

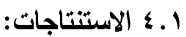

ا. غالبية العينة المبحوثة يشعرون بان الممارسات الخادعة تكون عن طريق مندوبي المبيعات لكونهم العنصر الذبي يقوم بتسويق وتقديم الخدمة

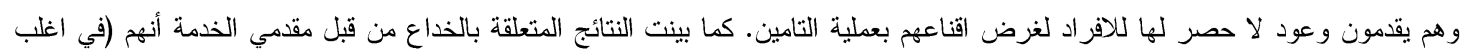

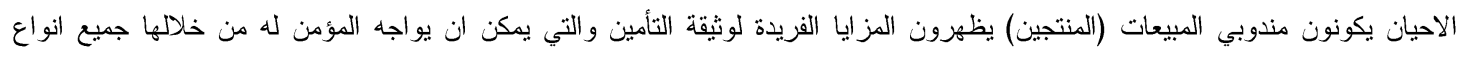

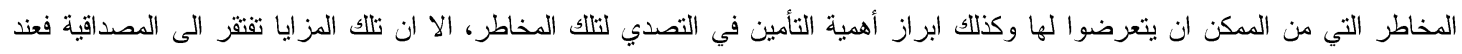

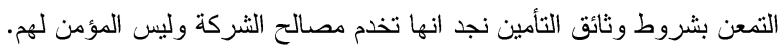

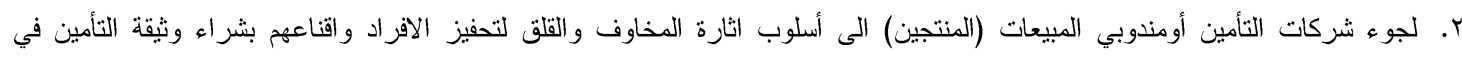

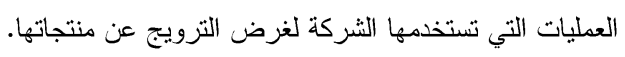
r. يرى الكثير من المؤمن لهم بان خدمات شركات التأمين في عملية التعويض تخضع للعديد من الاجر اءات التدقيقية وطلب المحاضر الخاصة

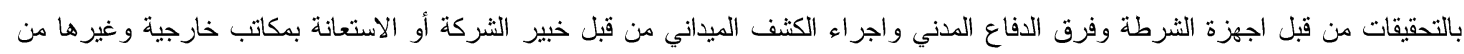

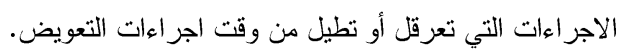

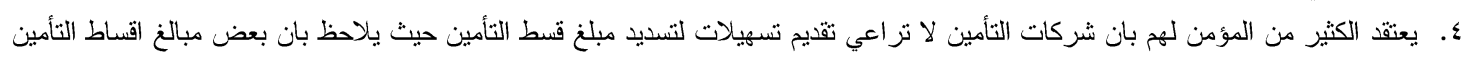

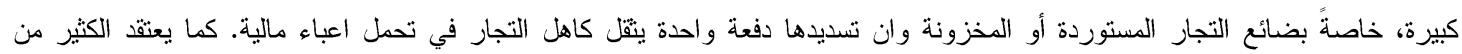

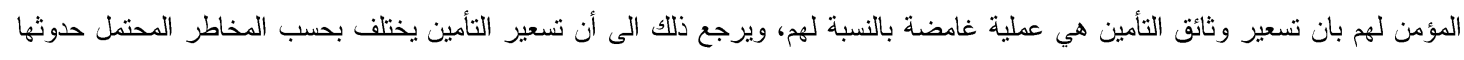
وكذلك نوع وقيمة البضاعة المؤمن عليها ومدة وصول البضاعة ونوع واسطة النقل، وكذلك اذا كان التأمين جماعي أو فردي (التأمين على الحياة

فقط )

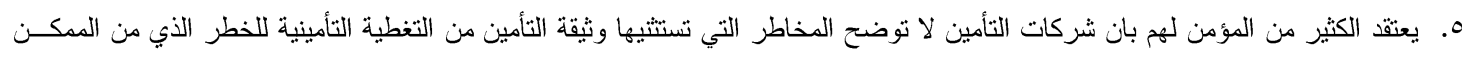
حدوثه فيذكر اغلب المؤمن لهم بان مندوبي المبيعات لا يقومون بتوضيح الظروف المتعلقة بحدوث الخطر لغرض شموله بالتغطية التأمينية. 
؟. الوصول الى الثركة يتطلب الكثير من الجهد والوقت لغرض متابعة عملية التأمين (كعمليات الكشف التي تسبق عملية التعويض أو الاتصال

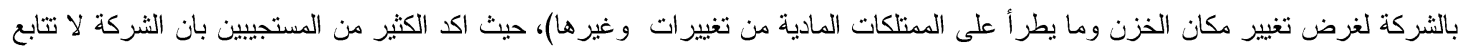

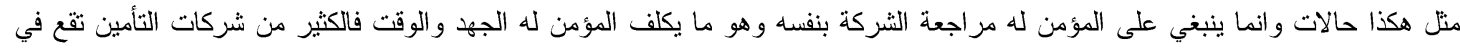

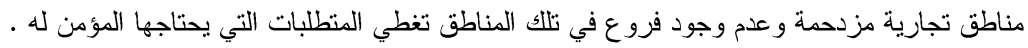

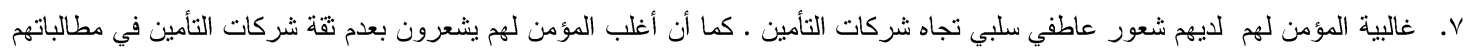
بالتعويض كما لو ان المؤمن له يمارس التضليل في الادعاءات و المطالبات التعويضية.

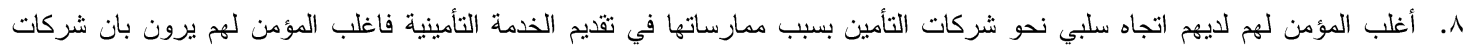

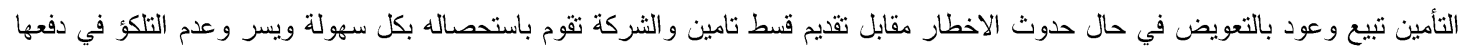

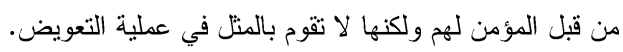

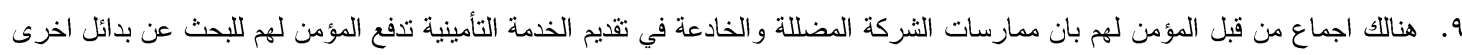
تلبي طموحاتهم ورغباتهم عن طريق التحري والاستقصاء من الزملاء في العمل أو الممارسين لنفس المهنة.

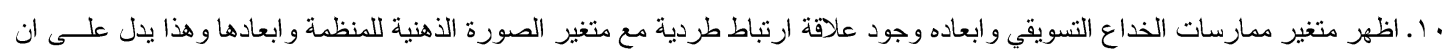

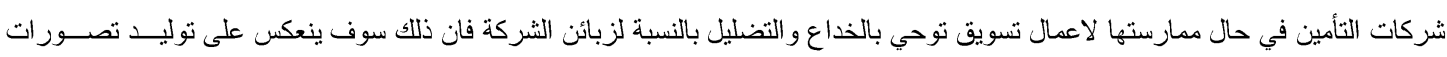

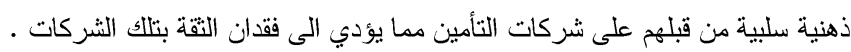

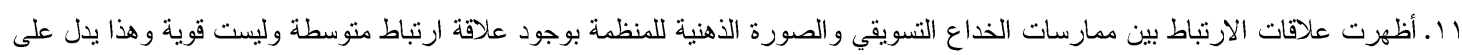

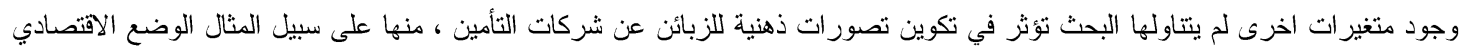

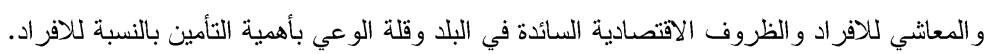
r ا. تؤثر الممارسات التسويقية الخادعة بشكل سلبي في التصور الذهني لزبائن شركات التأمين من خلال اساءة استعمال عناصر المزيج التسويقي للخدمات (الخداع في الخدمة التأمينية والخداع في السعر والخداع في التوزيع و الخداع في الترويج و الخداع عن طريق مقدمي الخدمة والخداع في لئي

عملية تقديم الخدمة).

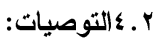

ا- ضرورة متابعة مندوبي المبيعات (المنتجين) وخاصةً المنتجين الخارجيين وعمل ورش عمل وتدريبهم على اخلاقيات المهنة في عمليات

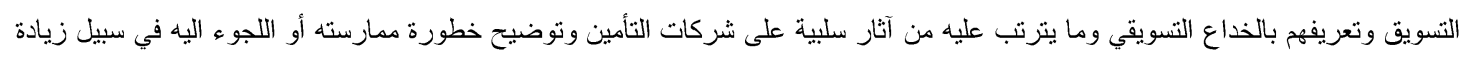

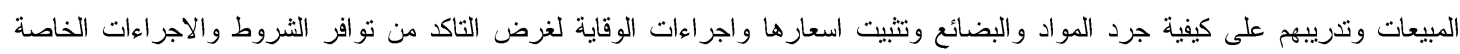

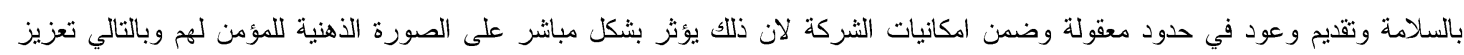

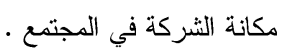
r- العمل على توضيح الثروط الواردة في وثيقة التأمين من قبل مندوب المبيعات (المنتجين) واحاطة المؤمن له باستثاءات وثيقة التأمين

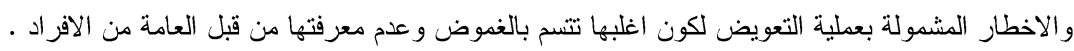

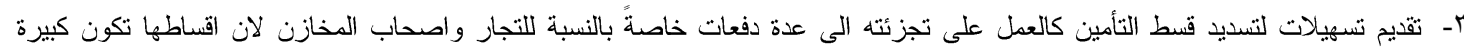
ويصعب تسديدها دفعة و احدة . ع- فتح فروع لثركات التأمين في المناطق التجارية كالثورجة ومنطقة جميلة الصناعية وتزويدها بكوادر قادرة على اجر اء الكثف في حالة

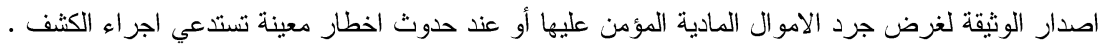

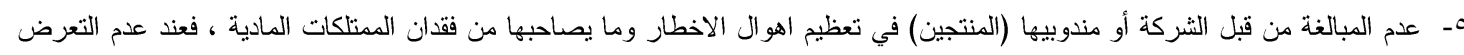

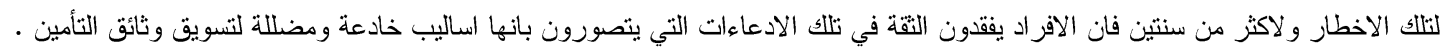

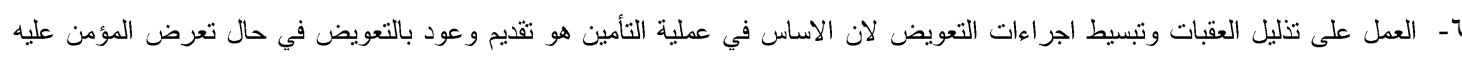

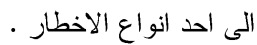
V- ابداء الثقة وحسن النية تجاه طالب التعويض من المؤمن لهم وخاصةً التجار واصحاب المصانع لان الاساس في عملية التأمين هو التكافل

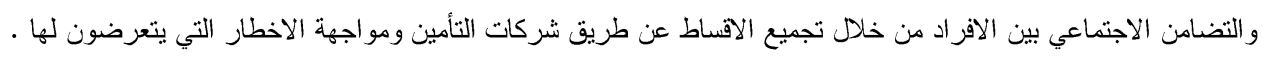

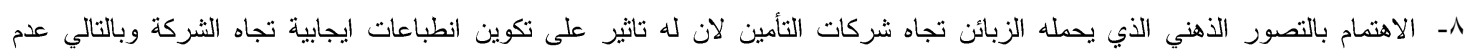
خسارة زبائن الثركة وكنلك كسب ثقة الافر اد الاخرين الذين يبحثّون عن تامين وبالتالي زيادة الحصة السوقية للثركة من خلال سمعتها في سوق التأمين. 9-- ضرورة تتكيل شعب أو لجان في شركات التأمين تاخذ على عاتقها النظر بالثكاوي المقدمة من قبل المؤمن لهم ومحاولة حسمها باسرع وقت ودون تاخير أو تلكؤء. • ا - الاستفادة من الخبرات العالمية في مجال التأمين ومحاولة اللحاق بالثركات العالمية بالتطور ات الحاصلة في قطاع التأمين. 


\section{CONFLICT OF INTERESTS}

$$
\text { 1ا-ضرورة الاستفادة من التطور الحاصل في مجال الاتصالات والانترنت واستعمال تطبيقات الحاسوب التي تسهل عملية التأمين. }
$$

There are no conflicts of interest.

$$
\text { - - المصادر }
$$

[1] Talwar, Reena, \& Ali, Saiyed Wajid, "Ethical Issues in Insurance Marketing in India: The Policy Holders' View" ", SAMVAD : SIBM Pune Research Journal , Vol 11 ,pp. 1-12, 2016.

[2] Bettignies, Henri-Claude de \& Lépineux, François \& Tan, Cheon Kheong, The Insurance Business and Its Image in Society: Traditional Issues and New Challenges, Working paper series INSEAD , 2006.

https://www.insead.edu/

[3] Palacio , Asunción Beerli \& Meneses, Gonzalo Díaz \& Pérez, Pedro J. Pérez, "The configuration of the university image and its relationship with the satisfaction of students", Journal of Educational Administration , Vol. 40 , Issue : 5 , pp. 486-505, 2002 .

[3] Agapito, D. \& Valle, P. \& Mendes, J., The cognitive-affective-conative model of destination image: A confirmatory analysis , Journal of Travel \& Tourism Marketing , 30 (5) , 471-481, 2013.

[4] Fayyaz, Nighum \& Lodhi, Samreen, Deceptive Advertising Practices and Customer Loyalty , European Journal of Business and Management, Vol.7, No.31, 2015.

[5] Aquino, Karl,"The effects of ethical climate and the availability of alternatives on the use of deception during negotiation", International Journal of Conflict Management Vol. 9 , No. 3 , pp. 195$217,1998$.

[5] Lee, Un-Kon, The Effect of Information Deception in Price Comparison Site on the Consumer Reactions: An Empirical Verification, International Journal of Distributed Sensor Networks Volume 2015.

[6] Sereikienè, Laima Abromaitytè, The Influence of Motivation Factor on Marketing Ethics in Lithuanian Media , Social Research / Socialiniai tyrimai. 2007. Nr. 2 (10), 5-12, 2007.

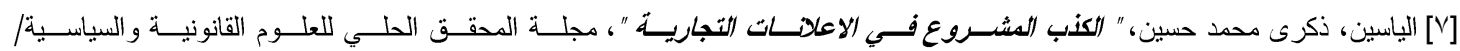

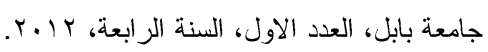

[8] Shimp , Terence A., Advertising Promotion and Other Aspects of Integrated Marketing Communications , Seventh Edition, Thomson South-Western, Printed in the United States of America, 2007.

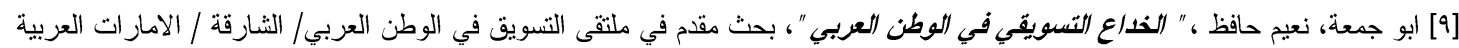

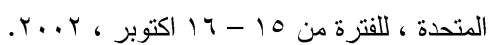

[10] Staake, Thorsten \& Thiesse, Frederic \& Fleisch, Elgar, The Emergence of Counterfeit Trade: A, Literature Review , European Journal of Marketing, Vol. 43 Iss: 3, 2009.

[11] Ford, Gary T. \& Calfee, John E., Recent Developments in FTC Policy on Deception , Journal of Marketing, Vol. 50, No. 3 (Jul., 1986), pp. 82-103, 1986 .

[12] Aditya, Ram N. , " The psychology of deception in marketing: A conceptual framework for research and practice.", Psychology \& Marketing, Vol 18 (7) , pp. 735-761, 2001.

[13] Wojdynski , Bartosz w. \& Evans, nathaniel j. \& hoy, mariea grubbs, " Measuring Sponsorship Transparency in the Age of Native Advertising " , Journal of Consumer Affairs, 52(1), pp. 115-137, 2017.

[14] Haas, Sandra \& Blasek, Katrin \& Raabe, Thorsten, Marketing Deceptions In German Practices: An Empirical And Legal Study On Published Cases On Marketing Deception, International Marketing Trends Conference, ISBN registration number 978-2-9532811-2-5 9782953281125, 2015.

$$
\begin{aligned}
& \text { [0 1 العاصي، فاطمة محمد احمد،" اثر الخداع التسويقي في بناء الصورة الذهنية للمستهلك في سوق الخدمات لاى شركات تزويد الاترنت }
\end{aligned}
$$

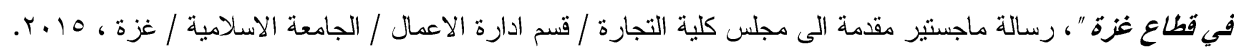




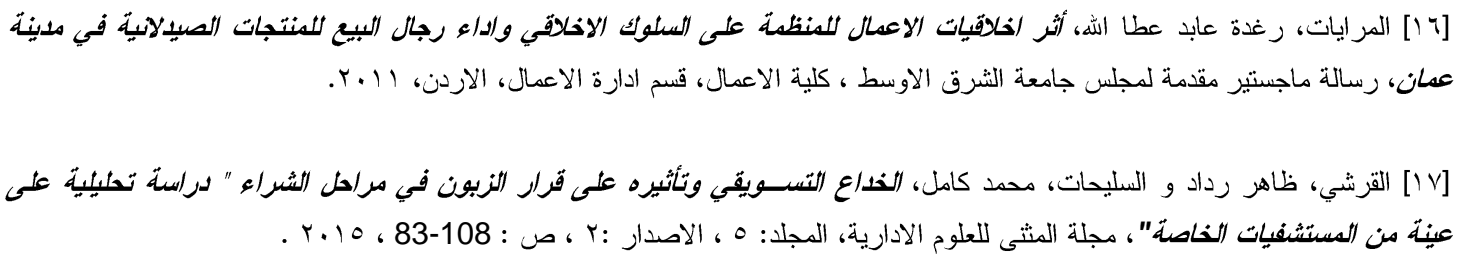

[18] Dastak, Ahmad Ghanbari, Aligholi, Mansoureh, Investigation of the Impact of Marketing Mix (8p) on Insurance Policy Purchase in Mellat Insurance Company in Alborz, Province, Iran , Journal of Applied Environmental and Biological Sciences , 4(11), 100-106, 2014.

[9 19] العامري، صالح مهدي محسن و الغالبي، طاهز محسن منصور، الادارة والاعمال، الطبعة الثانية، دار و ائل للنشر و التوزيع، عمان، الاردن،

[20] Plunkett, Daniel \& Budruk, Megha \& Lee, Woojin, Examining the impact of mental imagery visualization on place attachment: Destination marketing perspective, ttra International Conference Tourism Travel and Research Association: Advancing Tourism Research Globally, 2012.

[21] Malhotra, Archa, A Study of the Concept of Image as Expressed Through Corporate Landscapes, Thesis submitted to the faculty of the Virginia Polytechnic Institute and State University in partial fulfillment of the requirements for the degree of Master of Landscape Architecture , 2008.

[22] Nkempu , Zencha Lily, Communication In Image Building In The Experience Industry Case Study: Star Bowling Planet Ab , Master of Communication Thesis, University of Gothenburg, Department of Applied Information Technology, Gothenburg, Sweden , 2010.

[23] Sonnleitner, Katharina, Destination image and its effects on marketing and branding a tourist destination, A case study about the Austrian National Tourist Office - with a focus on the market Sweden, Master's Dissertation, Södertörn University, School of Business Studies , 2011.

[24] Topalian, Alan, Corporate identity: Beyond the visual overstatements, International Journal of Advertising, $3:(1)$, pp. 55-62, 1984.

[25] Abratt , Russell, A New Approach to the Corporate Image Management Process , Journal of Marketing Management, nt, 1989, 5 , No. 1, $63-76,1989$.

[26] Browning, Nicholas \& Gogo, Osenkor \& Kimmel, Marvin, "Comprehending CSR messages: applying the elaboration likelihood model ", Corporate Communications : An International Journal, 2017.

[27] Kandampully, Jay \& Hu , Hsin-Hui, Do hoteliers need to manage image to retain loyal customers?, International Journal of Contemporary Hospitality Management, Vol. 19, No. 6, pp. 435-443 , 2007.

$$
\begin{aligned}
& \text { [Y^] بوشهير، القاسم، أهمبة الاعالن في توجيك سلوك المستهلك ( دراسة حالة ), رسالة ماجستير مقدمة الى مجلس كلية العلوم الاقتصادية }
\end{aligned}
$$

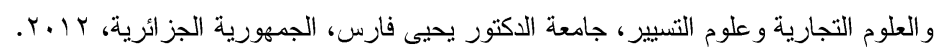

[29] Gartner, william c., " Image Formation Process ", journal of travel \& tourism marketing 2.2-3 , p.p. 191216, 1994.

[· r] كردي، احمد السيد طه، ادارة الصورة الذهنية للمنظمات في اطار واقع المسؤولية الاجتماعية، بحث مقدم الى قسم ادارة الاعمال ، كليــة

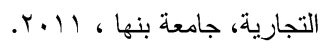

[31] Purolinna, Pirjo, University image and its effect on applying intentions Case: Aalto University School of Business, Master's thesis, Department of Marketing, Aalto University, School of Business, 2016.

[32] Pérez , Juana Patlán \& Torres, Edgar Martínez, Evaluation of the organizational image of a university in a higher education institution, journal of Contaduría y Administración , Volume 62 , 123-140 , 2017.

[33] Chowdhury, Saiful Kibria \& Salam, Monalisa , Predicting Attitude Based on Cognitive, Affective and Conative Components: An Online Shopping Perspective, Stamford Journal of Business Studies, Vol. 6 / 7, Issue II / I, December 2015 . 
[34] Basaran, Umit, Examining the Relationships of Cognitive, Affective, and Conative Destination Image: A Research on Safranbolu, Turkey, International Business Research , Vol. 9, No. 5, 2016 .

[35] Chen , Ching-Fu \& Tsai, DungChun, How destination image and evaluative factors affect behavioral intentions? , Tourism Management , V. 28, pp. 1115-1122, 2007. 